\title{
Il était une fois des contes en contextes : retour sur une expérimentation au primaire en Guadeloupe et au Québec
}

\author{
Lamprini CHARTOFYLAKA ${ }^{1}$, Frédéric ANCIAUX ${ }^{1}$, \\ Olivier-Serge CANDAU ${ }^{1}$, Béatrice JEANNOT-FOURCAUD ${ }^{1}$, \\ Isabelle CARIGNAN ${ }^{2}$ et Audrey SAINT-PIERRE ${ }^{2}$ \\ ${ }^{1}$ CRREF (EA 4538) - Université des Antilles \\ ${ }^{2}$ Université TÉLUQ
}

\section{Résumé}

Cet article décrit une expérimentation qui a été réalisée dans le cadre d'un programme de recherche plus large intitulé "Technologie éducative pour l'enseignement en contexte ». Cette itération s'appuie sur des apprentissages collaboratifs synchrones et asynchrones entre des élèves de Guadeloupe et du Québec, autour d'un objet d'enseignement particulier et commun, le conte. La méthodologie retenue est de type Design-Based Research, et ce, en collaboration avec l'enseignant titulaire de chacune des classes. Elle a consisté à faire travailler deux classes du primaire (élèves de 10 à 11 ans pour la Guadeloupe et de 10 à 12 ans pour le Québec), chacune travaillant sur un conte régional propre à son contexte, en vue d'échanger sur les différences et les ressemblances entre chaque conte, puis d'écrire un conte en commun à la fin de projet. Cette expérimentation a pour objectif de créer des effets de contexte, c'est-à-dire des décalages entre des conceptions d'élèves de deux contextes différents autour d'un objet précis. L'analyse des résultats montre que les élèves des deux territoires sont passés de conceptions majoritairement spontanées et acontextuelles du conte à des conceptions plus confirmées et contextuelles, voire bicontextuelles. Des pistes de réflexion didactique sont ensuite proposées en vue d'exploiter les effets de contexte dans la conception et la mise en œuvre de scénarios pédagogiques au primaire.

\section{Mots-clés}

Conte, primaire, Guadeloupe, Québec, effets de contexte, enseignement à distance.

\begin{abstract}
This article describes an experiment that was conducted as a part of a broader research project called "Educational Technology and Teaching in context" This study is based on synchronous and asynchronous collaborative learning between students from Guadeloupe and Quebec, with the collaboration of their teachers, around a particular and a common teaching object, namely storytelling. The chosen methodology is DesignBased Research. It involved two elementary classes (10-11 years old in Guadeloupe and 10-12 years old in Quebec), each working on a context-specific regional folktale, in order to discuss the differences and similarities between each story. This experimentation is based on the idea of creating context effects, meaning shifts between students' conceptions from two different contexts around a precise object of study. The results show that students in both territories have moved from naive and acontextual conceptions of storytelling to more expert, contextual, and even bicontextual conceptions. Ideas for reflection are then proposed in order to exploit the effects of context in the design and implementation of pedagogical scenarios in elementary school.
\end{abstract}

\section{Keywords}

Folktale, elementary school, Guadeloupe, Quebec, context effects, distance learning. 


\section{Introduction}

Cet article présente l'une des expérimentations menées dans le cadre d'un programme de recherche intitulé "Technologie éducative pour l'enseignement en contexte" (Forissier, Bourdeau et Psyché, 2018). Ce programme qui a débuté en 2016 a été réalisé en partenariat entre 1'Université des Antilles et l'Université TÉLUQ dans le cadre de l'appel à projets franco-québécois en sciences humaines et sociales financé par l'Agence Nationale de la Recherche de France (A.N.R.) et le Fonds de recherche Société et Culture du Québec (F.R.Q.S.C.). L'expérimentation présentée ici, appelée Itération Langue dans le cadre de ce programme de recherche, a pour but de faire travailler deux classes à distance, l'une en Guadeloupe et l'autre au Québec, autour d'un objet d'enseignement commun : le conte. L'objectif principal est de créer un scénario pédagogique susceptible de produire des effets de contexte (Delcroix, Forissier et Anciaux, 2013) entre les élèves des deux classes. En d'autres termes, le but est de confronter des écarts de conceptions entre des acteurs issus de deux contextes relativement à un ou plusieurs objets d'enseignement. Ces écarts doivent engendrer des réactions et des discussions liées aux apprentissages autour des spécificités de chaque contexte et de chaque conception. Ainsi, la création de scénario de ce type repose sur l'hypothèse selon laquelle la confrontation des contextes devrait enrichir les conceptions des élèves des deux contextes par rapport à leur conception initiale.

Dans ce qui suit, nous allons présenter de manière plus précise l'expérimentation menée et le choix du conte en tant qu'objet d'enseignement. Puis, nous exposerons la méthodologie de recherche employée ainsi que les principaux résultats. Enfin, nous discuterons ces résultats et envisagerons des pistes d'exploitation pédagogique et didactique.

\subsection{Présentation du projet initial de l'itération}

L'objectif initial que nous nous étions fixé était de proposer, comme objet d'enseignement, les variétés de français régionaux et de faire ainsi reposer l'élaboration du scénario pédagogique sur les spécificités du français parlé au Québec et sur celles du français parlé en Guadeloupe. Plusieurs études ont effectivement relevé des traits spécifiques, que ce soit au niveau lexical, syntaxique ou encore au niveau de l'intonation et de la prononciation entre le français québécois (Bigot, 2011; Santerre, 1981) et le français guadeloupéen (HazaëlMassieux et Hazaël-Massieux, 1996; Ludwig, Poullet et Bruneau-Ludwig, 2006). Ces différences nous paraissaient intéressantes pour confronter les élèves des deux territoires à des faits de langue particuliers dans le cadre de l'apprentissage de la forme standard de la langue française enseignée à l'école, tout en sachant que le français est en contact permanent avec une autre langue dans ces deux contextes, le créole pour la Guadeloupe et l'anglais pour le Québec.

Il est important de mentionner que nous avons abandonné l'idée de travailler les variétés du français pour nous concentrer sur un autre domaine de la discipline, la littérature, et plus précisément sur le conte. Certaines études ont proposé d'utiliser le conte pour l'apprentissage du français langue première (Popet et Roques, 2000) et langue étrangère, comme en Algérie (Zarior, 2016) ou au Burkina Faso (Diabaté, 2014), en montrant ses effets positifs sur l'apprentissage oral et écrit de la langue en améliorant la mémoire, la confiance en soi, le vocabulaire, la prise de parole ou encore l'imagination des élèves (Bettelheim, 1976) et les compétences en écriture (Yavuz et Celik, 2017). L'objectif de cette recherche est donc d'exploiter des contes issus de deux contextes culturels différents pour enrichir les connaissances de l'objet « conte », en lui-même, auprès d'élèves provenant de deux territoires 
distincts car il s'agit d'une dimension encore peu étudiée. Les questions de recherche vont comme suit : le conte peut-il constituer un objet d'enseignement pertinent pour créer des effets de contexte entre des élèves issus de deux territoires différents ? La confrontation des conceptions des élèves sur le conte de chaque territoire peut-elle enrichir leur connaissance générale sur le conte?

\subsection{Le choix du conte comme objet d'étude}

Le choix du conte s'efforce de répondre à deux exigences, l'une littéraire et l'autre pédagogique, qui sont indissociables l'une de l'autre par l'entremise des interactions qu'elles créent entre cultures, contextes et apprentissages à distance. La première est assez traditionnelle dans la mesure où elle précède le cadre même de l'expérimentation. Le conte est un objet littéraire à la fois singulier en ce sens qu'il reflète un contexte culturel, historique et social donné (il met en scène la lutte de l'homme face à la société) et universel, en ce qu'il apporte des réponses communes à des cultures différentes (il est porteur de valeurs morales intemporelles). La seconde est plus originale dans la mesure où elle relève plus particulièrement de notre expérimentation. Les vertus pédagogiques du conte auprès du jeune public (facilité apparente de la lecture et satisfaction attendue à son écoute) ne sont pas les seules à expliquer sa sélection. La lecture du conte, sa compréhension et son interprétation permettent aux élèves de s'identifier à un récit d'une façon simple et rassurante par la mise à distance des problèmes de leur propre existence (Boimare, 1992), tout en mobilisant un patrimoine culturel commun, le récit initiatique en particulier (Guillou, 2014).

À la fois proche et lointain d'un territoire à une autre, le conte suscite des effets de contexte plus ou moins attendus (l'identification aisée des traces culturelles pour les lecteurs d'un pays le sera moins pour les autres) voire inattendus (comment comprendre les contes de Perrault au $21^{\mathrm{e}}$ siècle alors que la forêt est désormais un lieu à défendre, sacralisé par l'écologie, et non plus à fuir comme il l'était au $17^{\mathrm{e}}$ siècle ?). Le déploiement d'un dispositif de visioconférence dans le cadre de ce projet, abolissant le temps des échanges et la distance géographique entre les territoires, met en évidence les effets de contexte en les rendant - par la combinaison du son et de l'image - immédiatement saisissables. Ceci permet donc de développer, pour les élèves, "la littératie médiatique multimodale appliquée » en contexte (Lacelle, Boutin et Lebrun, 2017). Pour ces auteurs, le concept de littératie médiatique multimodale peut être défini comme suit :

«capacité d'une personne à mobiliser adéquatement, en contexte communicationnel synchrone ou asynchrone, les ressources et les compétences sémiotiques modales (ex. : mode linguistique seul) et multimodales (ex. : combinaison des modes linguistique, visuel et sonore) les plus appropriées à la situation et au support de communication (traditionnel et/ou numérique), à l'occasion de la réception (décodage, compréhension, interprétation et évaluation) et/ou de la production (élaboration, création, diffusion) de tout type de message » (Lacelle, Boutin et Lebrun, $2017: 8$ ).

C'est notamment le développement de la littératie médiatique multimodale par les élèves qui a été mis en place dans le cadre de cette expérimentation. "Plus qu'un concept à définir, la littératie médiatique multimodale s'incarne dans la mission même de l'école et s'applique à toute programmation des cursus scolaires, de la maternelle à l'université » (Lacelle, Boutin et Lebrun, $2017: 8$ ).

Par ailleurs, après avoir expliqué dans les grandes lignes ce qui fait du conte un objet littéraire susceptible de faire émerger des effets de contexte, il reste à montrer qu'il est aussi un soutien à l'apprentissage capable d'avoir les mêmes effets. Pour comprendre l'intérêt de la découverte 
du conte par les élèves, il faut rappeler que le texte littéraire se doit d'être relié à un environnement culturel, historique et social. Cet ancrage environnemental soulève des questions d'ordre épistémologique, linguistique et didactique.

Sur le plan épistémologique, on peut se demander quels sont les savoirs mobilisés pour comprendre le conte. Il n'aura échappé à personne que le conte, attesté dans tous les pays et toutes les cultures, donne accès à l'histoire de la pensée humaine. Les aventures et les expériences des héros racontées dans les récits apportent bien des réponses aux grandes questions qui orientent l'existence de l'homme : le sens de la vie, la crainte de la mort, le Bien et le Mal. Les catégories se déclinent à l'infini. On se retrouve pourtant face à un écueil. Comment mesurer des écarts dans les conceptions des élèves à partir d'un texte dont la structure est profondément identique ? Comment être certains que les écarts de contexte ne se réduisent pas à des observations sur l'habillage des contes d'un pays à un autre (comme en atteste, par exemple, le recensement des figures européennes du Petit Chaperon rouge par Windmüller, 2008) et la transposition d'un personnage d'un pays à un autre (les aventures de Leuk-le-Lièvre, transcrites par Senghor et Sadji en 1953, sont assez proches de celles du Roman de Renart de Combaret du Brès et Saubrenat en 1981). L'entrée épistémologique n'est pas suffisante en tant que telle. Soit l'on considère que les contes d'un pays à un autre relèvent d'un habillage narratif différent, et dans ce cas, il faudrait admettre que l'effet de contexte est faible. Soit l'on se refuse à admettre que le conte relève d'une métastructure identifiable. C'est ce point de vue que nous défendrons ici.

Sur le plan linguistique, on peut se questionner sur les outils du langage propre au conte. C'est en effet en relisant les travaux de Lévi-Strauss (1973) que l'on peut trouver des éléments de réponse. Comme l'analyse précédente a permis de le pressentir, la question de l'universalité du conte relève de la gageüre. Si Lévi-Strauss reproche surtout à Propp (1958) d'évincer la question du lexique du conte, il attaque aussi son manque d'intérêt pour la dimension ethnographique. L'approche proppienne pourrait laisser croire que le conte ne s'expatrie hors de ses frontières d'origine qu'au prix d'une simplification morphologique vidée de son substrat lexical (typologie des actions observables dans le récit) et d'une contextualisation historique défaillante (pas d'ancrage du récit dans une réalité reconnaissable). Le principal reproche que Lévi-Strauss adresse à Propp tient d'abord à la réduction du conte à une structure linguistique ordinaire. Le conte proppien relève d'une forme linguistique traditionnelle assimilable à une structure phonologique. Depuis Saussure (1916), on sait qu'au signifié correspond de façon conventionnelle un signifiant acoustique. Les contraintes d'appariement entre les faits phoniques et les référents auxquels ils renvoient lorsqu'ils constituent des ensembles que sont les mots sont très importantes parce que les unités constitutives (les phonèmes) sont peu nombreuses et que les possibilités de combinaison sont très variées. La présence ou l'absence des phonèmes entraîne à elle seule la différenciation des mots entre eux. Les phonèmes favorisent ainsi le sens sans jamais le produire directement. La structuration du vocabulaire se fait donc à posteriori et non apriori (Lévi-Strauss, 1973 : 171).

On dira tout d'abord que la structure linguistique du conte opère à un double niveau : le premier relève d'un usage ordinaire du lexique et de la syntaxe (le signe renvoie à un référent extralinguistique), et le second d'un réseau formel et sémantique spécifique. On relira avec intérêt l'analyse de l'aigle et du hibou dans les contes des Indiens d'Amérique du Nord et du Sud (Lévi-Strauss, 1973 : 161-162). Le sens d'un terme se comprend à la fois sur le plan paradigmatique (à travers les relations qu'il entretient avec ceux du même champ notionnel, l'aigle et le hibou s'opposent sous le rapport du jour et de la nuit) et syntagmatique (à partir 
de son insertion dans un réseau relationnel étendu, déterminé dans un extrait donné). L'analyse anthropologique de Lévi-Strauss (1973) permet de montrer l'importance du point de vue ethnographique du contexte des croyances par exemple. L'étude du lexique dans le conte fait surgir la question des compatibilités et des incompatibilités entre les personnages notamment lorsqu'elles sont susceptibles d'éclairer le système très structuré des relations entre chacun. Les attributs prêtés aux personnages ne sont pas réductibles à des contingences privées de signification. En ce sens, les mythèmes pour Lévi-Strauss, que l'on entendra comme les unités élémentaires identifiables dans le mythe, remplacent les phonèmes dans l'analyse de Propp, pour se construire dans un jeu d'oppositions paradigmatiques et syntagmatiques. Assimilables à des mots, les mythèmes sont d'usage précontraint, et renvoient au double usage du langage, à la fois ordinaire (ils renvoient à une signification spécifique) et extraordinaire (ils se construisent dans un réseau complexe d'oppositions). Ils sont ainsi des :

«[...] mots de mots, qui fonctionnent simultanément sur deux plans, celui du langage où ils continuent de signifier chacun pour soi, et celui du métalangage où ils interviennent comme éléments d'une super-signification, qui ne peut naître que de leur union » (LéviStrauss, $1973: 171)$.

Sur le plan didactique, il s'agit de savoir en quoi les textes choisis se rattachent à une forme littéraire codée et à un genre identifiable. La mise en œuvre de cette itération repose sur la découverte et l'appropriation de contes, qui n'ont pas simplement comme vertu d'être des objets scolaires, mais qui ont comme fonction de recueillir les indices d'une construction identitaire culturelle forte. L'objectif est de montrer comment les élèves se saisissent des aventures et des expériences relatées dans les récits pour construire une réflexion sur leur propre vision du monde. Pour conclure cette partie, on dira que le choix du conte est :

- culturel: le conte est un objet de savoir privilégié pour faire émerger les représentations de chacun sur un patrimoine culturel collectif;

- linguistique : le sens des termes d'un conte à un autre se comprend donc à la fois sur le plan paradigmatique (à travers les relations qu'il entretient avec ceux du même champ notionnel) et syntagmatique (à partir de son insertion dans un réseau relationnel étendu, déterminé dans un extrait donné);

- didactique : on s'interroge ici sur le rattachement, par les élèves, de textes littéraires à une forme littéraire codée et identifiable à partir de laquelle ils construisent une vision du monde.

\subsection{Le choix du conte dans chaque territoire}

Dans le cadre de cette expérimentation, deux contes ont été choisis. Le premier pour la Guadeloupe s'intitule " Compère Zamba voulait tromper Compère Lapin » (cf. Annexe 1) et le second pour le Québec s’intitule « Rose Latulipe » (cf. Annexe 2).

\subsubsection{Le conte de la Guadeloupe}

Comme noté précédemment, le conte en tant qu'objet universel apporte des réponses aux grandes questions qui se posent à l'Homme. Produit dans des contextes spécifiques, le conte a cependant une vocation à aborder de façon plus fine les questionnements propres à chaque communauté et à apporter les réponses les plus appropriées en fonction des problématiques qui y sont considérées comme majeures et qui sont relayées de génération en génération. Ainsi, aux Antilles, le conte est lié de façon très intime à l'histoire coloniale (voir notamment Relouzat, 1989, 1998 ; Césaire, 1981) et aux rapports sociaux qui en découlent, « rapports de pouvoir qui existaient et qui existent encore, toutes proportions gardées, entre, d'un côté, les 
petits, les faibles, les esclaves et, de l'autre, les forts, les maîtres, les Blancs » (Jardel, 1977 : 10). L'un des thèmes récurrents traité dans les contes est celui de la ruse et de la débrouillardise, laquelle même si elle " entraîne de la part des héros des actes non conformes au système dominant, est valorisée » (Jardel, 1977: 11). Les deux figures emblématiques, humaine et animale, qui représentent la débrouillardise sont respectivement Tijan et Compère Lapin (Césaire, 1981). C'est ce dernier personnage qui est au centre du conte choisi en Guadeloupe. Ce dernier s'inscrit dans un cycle de contes autours de Compère Lapin, mais également de son alter ego, Compère Zamba, qui symbolise la force brute, dont vient toujours à bout Compère Lapin.

Dans « Compère Zamba voulait tromper Compère Lapin », Zamba, cultivateur, ne s'occupe guère de ses plantations, car il estime avoir mieux à faire. Il compte ainsi toujours sur Compère Lapin ou sur d'autres compères pour lui fournir la nourriture dont il a besoin. Cependant, il vient un moment où plus personne ne souhaite le nourrir. Il propose donc à Compère Lapin de cultiver ensemble un même terrain : Compère Lapin récoltera ce qui aura poussé sous la terre et Compère Zamba ce qui aura poussé à l'extérieur. Si Zamba se garde bien de venir aider Lapin pour l'entretien du champ, il se manifeste au moment de la récolte et a la désagréable surprise de constater que toute la production se trouve sous terre (Lapin n'ayant planté que des racines comestibles). Zamba propose le même marché à Lapin l'année suivante, mais cette fois-ci, Compère Lapin récoltera ce qui aura poussé en surface et lui ce qui aura poussé sous terre. Comme l'année précédente, Zamba disparaît dès qu'il est question d'entretenir le champ et Compère Lapin décide de ne planter que des graines dont les fruits sortiront hors de terre. Zamba se retrouve donc à nouveau victime de sa propension à vouloir profiter d'autrui. La morale, explicite, qui clôt ce conte est « Être paresseux c'est contre soimême. Seuls l'effort et le travail paient». Mais l'on peut surtout y déceler à partir des référents ethnoculturels repérés (Relouzat, 1989), que le conte se termine par la victoire de l'opprimé, du faible sur le profiteur, le fort.

\subsubsection{Le conte du Québec}

La légende acadienne «Rose Latulipe» (Aubert de Gaspé, 2006), relevant des récits traditionnels du «Diable à la danse » et du «Diable beau danseur » (Demers et Gauvain, 1976) se déroule au $18^{\mathrm{e}}$ siècle et présente une image vivante des mœurs. Dans ce récit, une jeune coquette, pourtant fiancée, risque le salut de son âme en acceptant de danser avec un bel étranger, qui est en réalité le Diable incarné. Passant outre les recommandations du curé et de son père, elle satisfera sa passion de la musique et de la danse au-delà de minuit. La mort en sera le prix à payer. C'est peut-être dans la composition même de chaque récit que se joue l'unité du recueil de contes d'Aubert de Gaspé. Chacun a recours à la même organisation narrative (Cormier, 2006) de séquences identifiables articulées autour des personnages principaux (l'Héroïne, une jeune écervelée transgressant l'interdit, l'Adversaire, le Diable sous les traits d'un beau jeune homme et l'Aide, le curé doté d'un pouvoir surnaturel parvenant à chasser l'Adversaire). La fin du récit est généralement marquée par le retour à l'équilibre heureux (le repentir de l'Héroïne) ou malheureux (la mort de l'Héroïne) et la réparation des torts vis-à-vis de la communauté. Le conte témoigne alors d'une fonction de régulation sociale (par la répression des conduites déviantes occasionnant une rupture dans le groupe) et expressive (par la manifestation des tensions entre nature et culture, ordre et raison qui guident les choix des membres de la communauté). 
Le conte "Rose Latulipe » respecte la structure linéaire du schéma narratif traditionnel en cinq temps : la situation initiale, la complication (ou élément déclencheur), les actions, la résolution (ou dénouement) et la situation finale (Adam, 1992). Les personnages stéréotypés échappent à toute complexité. Enfin, une morale implicite, soit l'antithèse Bien-Mal, émerge à la toute fin et celle-ci est directement liée à la tradition judéo-chrétienne : il ne faut pas tenter le diable, sinon nous serons punis. En effet, la pauvre Rose meurt à la fin, même s'il s'agit de cinq ans après l'altercation avec le diable.

\subsection{Les effets de contexte}

Comme nous l'avons déjà mentionné, le conte ne se limite pas à une structure narrative universelle à laquelle chaque pays fournirait un habillage formel. La contextualisation du conte (entendue ici comme l'ancrage culturel nécessaire à son appropriation) constitue un fondement essentiel, tant sur le plan épistémologique, linguistique que didactique, pour en appréhender le sens. Vouloir saisir les effets de contexte nécessite un cheminement d'un bout à l'autre de la chaîne littéraire : depuis la production du récit (en la rattachant à un horizon culturel donné) jusqu'à sa réception (sa compréhension, son interprétation et son appréciation esthétique). Ainsi, pour observer et analyser les effets de contexte, il est important de s'intéresser à deux domaines relatifs aux faits de langue en usage dans le conte :

- la compréhension (à travers les composantes grammaticales fondamentales: la phonologie, la morphologie, la syntaxe et la sémantique) liée davantage au domaine linguistique ;

- l'usage (à travers l'interprétation que les énoncés reçoivent en contexte) lié au domaine extralinguistique et qualifié de pragmatique (Moeschler et Reboul, 1994).

Parmi les différents domaines de la linguistique, c'est certainement la lexicologie, entendue comme l'étude du lexique relatif à la forme des mots, et la sémantique, entendue comme la signification et la combinaison des mots (Gardes-Tamine, 1998 : 116), sur lesquelles il faudra s'attarder davantage. Nous allons donc mettre l'accent sur l'existence ou non, dans l'ensemble du lexique lié au conte construit par les élèves de Guadeloupe et ceux du Québec, d'ensembles et de sous-ensembles qui seraient mobilisés de façon identique.

\section{Méthodologie}

Cette partie est consacrée à la présentation de l'ensemble du dispositif mis en place pour la réalisation de cette expérimentation. Nous rappelons que cette dernière fait partie d'un programme de recherche plus large, étalé sur trois ans (Forissier, Bourdeau et Psyché, 2018). Il s'agit de la quatrième itération, l'itération Langue, menée au sein de ce programme. Ce dernier utilise une méthodologie de type Design-Based Research (2003) qui repose sur une série d'itérations permettant d'expérimenter un modèle et une stratégie d'enseignement particuliers, de valider des hypothèses et d'affiner des instruments spécifiquement élaborés pour cet objectif. Les itérations précédentes ont permis d'ajuster les modalités de scénarisation pédagogique et de recueil de données selon un principe de boucle itérative qui consiste à mener une réflexion conjointe entre théorie et pratique, entre didactique et pédagogie, entre conception et réalisation du scénario, entre chercheurs et enseignants, sans que les étapes se distinguent réellement.

Nous présentons dans un premier temps les personnes impliquées dans la conception et la réalisation de cette itération ainsi que la population d'étude. Ensuite, les différents outils utilisés et leurs objectifs respectifs sont détaillés. Puis, nous expliquons l'ensemble des étapes 
du déroulement de l'étude. Enfin, les différentes méthodes d'analyses des données sont exposées.

\section{1. Équipe de recherche et population d'étude}

L'équipe de recherche à l'initiative de cette expérimentation est composée de six personnes, dont trois enseignants-chercheurs et une étudiante en doctorat en Guadeloupe, ainsi qu'une professeure-chercheure et une étudiante de maîtrise au Québec. Cette équipe de recherche a travaillé en partenariat avec deux enseignants : le premier en Guadeloupe avec une classe de CM2 composée de 20 élèves âgés de 10 à 11 ans (10 garçons et 10 filles) et le second au Québec avec une classe de $5^{\mathrm{e}}$ et $6^{\mathrm{e}}$ année composée de 15 élèves âgés de 10 à 12 ans $(8$ garçons et 8 filles). En réalité, au Québec, 17 élèves au total ont participé, mais un élève a rejoint la classe après le début des séances (il n'y a pas de pré-test pour cet élève) et un élève n'a pas fait le post-test. Ainsi pour notre analyse, on a retenu les réponses de 35 élèves qui ont participé tout au long de cette expérimentation.

\subsection{Outils méthodologiques utilisés}

Plusieurs outils ont été conçus et utilisés dans le cadre de cette itération. Le premier outil est un questionnaire destiné aux élèves de chaque territoire en vue de recueillir leurs conceptions par rapport au conte. Ce questionnaire a été distribué à l'ensemble des élèves au début et à la fin de l'itération. L'objectif était d'analyser l'évolution de leurs connaissances relativement au conte ainsi que les changements conceptuels éventuels opérés au cours de l'itération. Le questionnaire initial (pré-test) est composé de 9 questions et le questionnaire final (post-test) est composé de 10 questions. Ce dernier reprend exactement les mêmes questions que le prétest, mais une dixième question a été ajoutée afin de recueillir l'avis des élèves sur ce qui les a impressionnés ou surpris lors des échanges avec les élèves de l'autre classe au cours de l'expérimentation lors des visioconférences Québec-Guadeloupe (cf. Annexe 3).

Concernant l'organisation du questionnaire et le contenu des questions, les quatre premières portent sur le conte d'un point de vue général. Elles demandent notamment aux élèves s'ils aiment les contes, à quoi ils servent et ce qu'est un conte pour eux. Il leur est également demandé de faire un dessin qui reflète ce à quoi ils pensent quand ils entendent le mot « conte ». En effet, « as plenty of research has shown, young children cannot always articulate their ideas and feelings - but they can often show their meaning-making through their artistic creations $»^{1}$ (Arizpe et Styles, $2016: 8$ ). Un entretien individuel a également été réalisé à la fin de l'itération avec chaque élève afin qu'il puisse expliquer ce qu'il a voulu représenter dans son dessin selon un protocole établi (cf. Annexe 4). Les cinq dernières questions portent respectivement sur cinq thématiques choisies autour du conte : les expressions et le lexique, les personnages, les lieux, le schéma narratif et les références culturelles. Chacune de ces questions demande aux élèves de donner des informations sur chacune de ces thématiques.

\subsection{Déroulement}

Le travail de collaboration entre milieux scolaires et universitaires de la Guadeloupe et du Québec a débuté en septembre 2017. Il a consisté, dans un premier temps, à concevoir un scénario pédagogique identique qui sera mené de manière synchrone sur les deux territoires.

\footnotetext{
${ }^{1}$ Nous traduisons : «Comme plusieurs recherches l'ont montré, les jeunes enfants ne peuvent pas toujours exprimer leurs idées et leurs sentiments, mais ils peuvent souvent construire du sens à travers leurs créations artistiques. »)
} 
Le scénario élaboré repose sur un total de douze séances et prévoit différents types de travail en salle de classe :

- un travail effectué par l'enseignant avec les élèves en salle de classe ;

- un travail effectué par équipe en sous-groupes d'élèves en salle de classe ;

- un temps d'échanges par visioconférence entre les deux classes (Guadeloupe et Québec);

- un temps d'échanges par visioconférence entre les équipes-miroirs ${ }^{2}$ de chaque territoire.

Ces douze séances ont été réalisées sur une période d'environ un mois, entre avril et mai 2018. Le tableau 1 présente l'organisation de ces différentes séances.

\begin{tabular}{|c|c|c|c|c|c|c|}
\hline$N^{\circ}$ de séance & $\begin{array}{c}\text { Séance } \\
1\end{array}$ & $\begin{array}{c}\text { Séance } \\
2\end{array}$ & $\begin{array}{c}\text { Séance } \\
3\end{array}$ & $\begin{array}{c}\text { Séance } \\
4\end{array}$ & $\begin{array}{c}\text { Séance } \\
5\end{array}$ & $\begin{array}{c}\text { Séance } \\
6\end{array}$ \\
\hline Guadeloupe & \multirow{2}{*}{$\begin{array}{c}1^{\text {ère }} \\
\text { Visio Groupe } \\
\text { Classe }\end{array}$} & \multirow{2}{*}{$\begin{array}{c}2^{\text {ème }} \\
\text { Visio Groupe } \\
\text { Classe }\end{array}$} & $\begin{array}{l}\text { Travail en } \\
\text { équipe }\end{array}$ & \multirow{2}{*}{$\begin{array}{l}1^{\text {ère }} \\
\text { Visio Équipes- } \\
\text { Miroirs }\end{array}$} & $\begin{array}{l}\text { Travail en } \\
\text { équipe }\end{array}$ & $\begin{array}{l}\text { Travail en } \\
\text { équipe }\end{array}$ \\
\hline Québec & & & $\begin{array}{l}\text { Travail en } \\
\text { équipe }\end{array}$ & & $\begin{array}{l}\text { Travail en } \\
\text { équipe }\end{array}$ & $\begin{array}{l}\text { Travail en } \\
\text { équipe }\end{array}$ \\
\hline Dates & $10 / 04 / 18$ & $13 / 04 / 18$ & $16 / 04 / 18$ & $17 / 04 / 18$ & $20 / 04 / 18$ & $24 / 04 / 18$ \\
\hline $\mathbf{N}^{\circ}$ de séance & $\begin{array}{c}\text { Séance } \\
7\end{array}$ & $\begin{array}{c}\text { Séance } \\
8\end{array}$ & $\begin{array}{c}\text { Séance } \\
9\end{array}$ & $\begin{array}{c}\text { Séance } \\
10\end{array}$ & $\begin{array}{c}\text { Séance } \\
11\end{array}$ & $\begin{array}{c}\text { Séance } \\
12\end{array}$ \\
\hline Guadeloupe & $\begin{array}{l}\text { Travail en } \\
\text { équipe }\end{array}$ & $\begin{array}{l}\text { Travail en } \\
\text { équipe }\end{array}$ & \multirow{2}{*}{$\begin{array}{l}2^{\text {ème }} \\
\text { Visio Équipes- } \\
\text { Miroirs }\end{array}$} & $\begin{array}{l}\text { Travail en } \\
\text { équipe }\end{array}$ & \multirow{2}{*}{$\begin{array}{l}3^{\text {ème }} \\
\text { Visio Équipes- } \\
\text { Miroirs }\end{array}$} & \multirow{2}{*}{$\begin{array}{c}3^{\text {ème }} \\
\text { Visio Groupe } \\
\text { Classe }\end{array}$} \\
\hline Québec & $\begin{array}{l}\text { Travail en } \\
\text { équipe }\end{array}$ & $\begin{array}{l}\text { Travail en } \\
\text { équipe }\end{array}$ & & $\begin{array}{l}\text { Travail qui } \\
\text { équipe }\end{array}$ & & \\
\hline Dates & $27 / 04 / 18$ & $04 / 05 / 18$ & $07 / 05 / 18$ & 09/05/18 & $11 / 05 / 18$ & $14 / 05 / 18$ \\
\hline
\end{tabular}

\section{Tableau 1 : Organisation des séances}

La $1^{\text {ère }}$ séance était consacrée à une prise de contact entre les deux classes et à la découverte du projet sur lequel les élèves allaient travailler. Pour ce faire, chaque classe a préparé une présentation de son territoire et de son école qu'elle a ensuite partagée avec l'autre classe par visioconférence. Cette visioconférence regroupait donc l'ensemble des élèves et les deux enseignants. Après cette phase de présentation, les élèves ont été répartis en petits groupes dans chaque classe (Guadeloupe et Québec). Ensuite, à titre d'élément déclencheur, des enveloppes contenant chacune quatre images, en lien avec les contes (cf. Annexe 5), ont été distribuées à chaque groupe d'élèves. Les élèves devaient trouver à quoi ces images pouvaient faire référence. Après quelques minutes, les élèves ont trouvé qu'il s'agissait du «conte». Les enseignants leur ont annoncé qu'ils allaient travailler ensemble sur la thématique du conte.

La $2^{\text {ème }}$ séance s'est également déroulée avec l'ensemble des deux classes par visioconférence. L'objectif était de discuter du conte et de trouver des thématiques spécifiques sur lesquelles de petits groupes d'élèves (équipes-miroirs) allaient pouvoir travailler dans les deux contextes (Guadeloupe et Québec). Après avoir posé une question de

\footnotetext{
${ }^{2}$ Les équipes-miroirs sont deux groupes de 4 à 5 élèves, un groupe dans chaque territoire, qui travaillent sur le même objet et qui sont amenés à échanger au cours du scénario pédagogique. Par exemple, il y avait une équipe « personnages » au Québec et une autre en Guadeloupe.
} 
départ qui était «Qu'est-ce que c'est qu'un conte pour vous? », les élèves des deux classes ont échangé à tour de rôle et cinq thématiques ont été sélectionnées. Ces cinq thèmes, généralement étudiés lors de l'enseignement du conte, ont été choisis de façon à concevoir les activités lors de chaque séance. Ils ont également servi à la conception du questionnaire distribué au début et à la fin de l'expérimentation. Les thèmes retenus susceptibles de créer des effets de contexte sont le schéma narratif, les personnages, les lieux, les expressions et le lexique ainsi que les références culturelles. Les élèves de la Guadeloupe et du Québec se sont répartis en petits groupes dans chaque classe en choisissant le thème sur lequel ils souhaitaient travailler, ce qui a permis de constituer les équipes-miroirs.

Les séances 3, 5, 6, 7, 8 et 10 étaient des séances de travail en équipes-miroirs au sein de la classe sans interaction avec leurs homologues de l'autre territoire. Les séances 4, 9 et 11 étaient des séances en visioconférence entre les différentes équipes-miroirs des deux territoires. La séance 4 avait pour objectif de faire établir par chaque équipe-miroir une méthode d'enquête pour travailler sur le thème retenu, la séance 9 permettait à chaque équipemiroir de présenter ses résultats à leur homologue, et la séance 11 faisait réfléchir les équipesmiroirs à ce qu'elles pourraient conserver de leur conte respectif pour écrire un conte commun lié à chaque thème.

Lors de la séance 12, une visioconférence a été effectuée avec l'ensemble des élèves provenant des deux classes. Il s'agissait de dresser un bilan pour chaque équipe, de présenter leurs résultats à l'ensemble de la classe, puis d'envisager ce que chacun avait choisi de conserver pour l'écriture du conte commun.

Toutes les visioconférences en groupes classes ou en équipes-miroirs ont été réalisées et enregistrées à l'aide du logiciel Zoom ${ }^{3}$. Concernant les enregistrements vidéos, trois visioconférences en groupe classe (d'une durée de 30 à 45 minutes chacune, soit un total de deux heures d'enregistrement) sont disponibles, ainsi que trois visioconférences pour chacune des cinq équipes-miroirs (d'une durée de 20 minutes, soit près de cinq heures d'enregistrement).

De plus, un environnement numérique de travail propice à l'apprentissage a été proposé aux élèves et aux enseignants afin qu'ils puissent, d'une part, échanger en groupes classes de manière générale ou en équipes-miroirs thématiques, et d'autre part, déposer leurs travaux et leurs productions respectives. Il s'agit d'une plateforme collaborative appelée Edmodo ${ }^{4}$ L'ensemble des échanges sur Edmodo reste disponible pour une analyse ultérieure.

Enfin, tous les élèves, soit 36 élèves au total, ont été filmés lors de leur entretien individuel final lié à l'interprétation du dessin, ce qui constitue un corpus de trois heures d'enregistrement qui sera également analysé ultérieurement.

Au terme de cette itération, nous disposons de plusieurs types de données à analyser :

- les réponses des élèves au questionnaire au pré-test et au post-test par territoire ;

- les enregistrements des réponses des élèves lors de l'entretien sur les dessins qu'ils ont produits ;

- les données vidéos des visioconférences (Zoom);

- les échanges sur la plateforme collaborative (Edmodo);

- la production finale du conte écrit en commun entre la Guadeloupe et le Québec.

\footnotetext{
${ }^{3}$ Ce logiciel est accessible à l'adresse suivante : https://zoom.us/fr-fr/zoomrooms/software.html.

${ }^{4}$ Cette plateforme est accessible à l'adresse suivante : https://www.edmodo.com/.
} 
Dans cet article, nous analysons uniquement les réponses des élèves aux questionnaires distribués avant et après l'itération afin d'identifier et de comparer leurs conceptions initiales du conte dans chaque territoire, ainsi que leur évolution. Les autres données feront l'objet d'autres articles ultérieurement.

\subsection{Méthodes d'analyse des données}

Trois types d'analyses ont été utilisés pour étudier les réponses des élèves aux questions. La première est une analyse de contenu dont l'objectif est de repérer les catégories pouvant regrouper certains mots dans un ensemble plus vaste. La seconde est une analyse quantitative dont le but est de mesurer le nombre d'occurrences de certains mots en fonction des territoires et du moment de passation du questionnaire. La troisième analyse a consisté à évaluer le niveau d'expertise et le niveau de contextualité des réponses des élèves des deux territoires aux différentes questions retenus dans cet article au pré-test et au post-test.

\subsubsection{Analyse de contenu}

Une analyse de contenu a été utilisée pour traiter les données colligées à l'aide du questionnaire. En effet, l'analyse de contenu, par nature qualitative (Bardin, 2007), permet de décrire, de clarifier, de comprendre ou d'interpréter une réalité (Denzin et Lincoln, 2005). Ce type d'analyse a pour but d'analyser le discours (Gauthier, 2003) par le découpage des écrits en unités de sens (découpage sémantique) et le codage de ces unités de sens selon une grille d'analyse établie au préalable en reliant l'ensemble aux différentes thématiques émergeant du questionnaire. Elle fournit ainsi une analyse riche du corpus dans son ensemble.

Ainsi, à partir de mots ou de groupes de mots, nous avons établi des catégories de réponses que l'on a classées selon deux axes principaux. Le premier concerne la dimension contextuelle des réponses et peut être divisé en quatre niveaux distincts. Le premier niveau est appelé «acontextuel» quand les réponses portent sur des éléments hors du contexte spécifique des élèves, ici les contes européens ou les dessins animés, par exemple. Le second niveau est qualifié de « contextuel » quand les réponses correspondent à des éléments propres au contexte de l'élève, ici le conte créole pour les élèves de Guadeloupe ou le conte québécois pour les élèves du Québec. Le troisième niveau est appelé «bicontextuel» quand des éléments de contes issus de deux contextes différents sont évoqués. Enfin, le quatrième niveau est nommé «multicontextuel» lorsque les réponses des élèves comportent des éléments sur leur contexte propre ainsi que sur d'autres contextes, ici les contes créoles, québécois et européens.

Le second axe concerne la dimension d'expertise. Là aussi, nous avons classé les réponses selon trois niveaux, un niveau «spontané » qui témoigne d'un vocabulaire naïf et spontané, un niveau "confirmé » où les réponses font apparaître des éléments plus divers, précis et spécifique, et un niveau « expert » qui relève d'une maîtrise des notions relatives à l'objet et de réponses nuancées. En croisant ces deux dimensions contextuelles et d'expertise, dans le traitement des réponses, on peut ainsi obtenir différents profils, tels qu'une réponse « acontextuelle» et «spontanée », laquelle pourrait constituer une réponse naïve d'un élève non relative à son contexte, ou une réponse «multicontextuelle» et «experte» qui témoignerait d'un vocabulaire spécifique et de références à plusieurs contextes. 


\subsubsection{Analyse quantitative}

Une analyse quantitative a également été opérée à l'aide du logiciel Antcont ${ }^{5}$ sur l'ensemble des réponses des élèves en vue de relever la fréquence d'apparition des mots et d'occurrences de certains groupes de mots entre les territoires (Guadeloupe versus Québec) et en fonction des moments de passation du questionnaire (pré-test versus post-test). Il faut noter que la fréquence d'apparition des mots est relative au nombre d'élèves dans chaque territoire, soit 20 en Guadeloupe et 15 au Québec.

\section{Analyse quantitative des réponses des élèves}

Nous présentons ici une analyse spécifique des réponses données par les élèves uniquement aux questions 3, 5, 6 et 7 portant respectivement sur ce qu'est un conte, sur le lexique et les expressions, les personnages et les lieux. Puis nous procédons à une synthèse des résultats en vue de discuter des conceptions au sein de chaque territoire et de leur évolution au cours de l'expérimentation tant sur le plan de leur contextualité et de leur expertise.

\subsection{Question n³ : «Pour toi, qu'est-ce qu'un conte ?»}

Cette question portait sur la conception générale que les élèves pouvaient avoir d'un conte. On peut signaler que 6 élèves de Guadeloupe sur les 20 interrogés n'ont pas répondu à cette question au pré-test, alors qu'ils y ont tous répondu au post-test. Au Québec, la totalité des élèves, soit les 15 élèves, ont répondu à cette question tant au pré-test qu'au post-test. Les mots les plus fréquemment utilisés et regroupés dans l'unité de sens "conte » sont présentés dans le graphique 1 . Une première analyse de contenu effectuée sur les réponses a permis d'identifier cinq principales catégories ou unités de sens :

- 1/ la définition de ce qu'est un « conte »;

- 2/ les « personnages » que l'on retrouve dans les contes;

- 3/ les « sentiments » que l'on peut ressentir en lisant ou en écoutant un conte ;

- 4/ les « caractéristiques » du conte ;

- 5/ les « lieux » propres au conte.

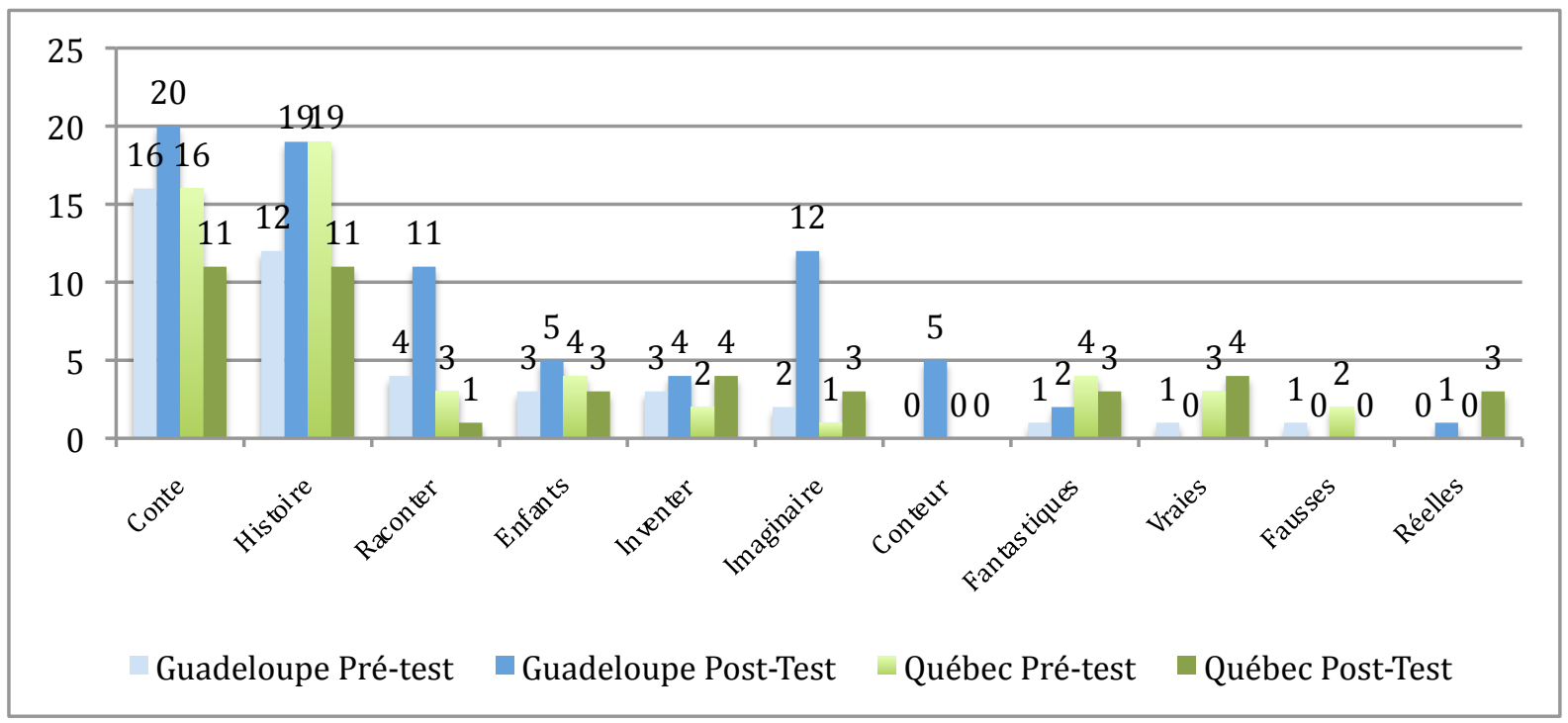

Graphique 1 : Fréquence d'apparition des mots concernant le conte

\footnotetext{
${ }^{5}$ Ce logiciel est accessible à l'adresse suivante : http://www.laurenceanthony.net/software.html.
} 
Pour les élèves interrogés, le conte est en général une histoire inventée, imaginaire, fausse et fantastique ou vraie et réelle que l'on raconte aux enfants. Si certaines occurrences de mots, comme enfants, inventer ou fantastique, ne varient pas ou peu d'un territoire à l'autre, ainsi qu'aux deux moments de passation, on peut relever trois mots qui prennent de l'importance au post-test, et ce, notamment en Guadeloupe. Les mots raconter, imaginaire et conteur ont une fréquence d'apparition plus élevée au post-test qu'au pré-test en Guadeloupe. En revanche, ces mots sont très peu apparus au Québec, voire pas du tout pour le mot conteur. Cette augmentation de ces trois mots pourrait illustrer le fait que les élèves de Guadeloupe ont perçu la dimension orale du conte, fortement présente dans les contes créoles, en insistant sur le fait qu'ils doivent être racontés par un conteur. On peut supposer que les élèves de Guadeloupe ont une conception plus experte et contextuelle du conte à la fin de l'expérimentation.

Pour les élèves du Québec, il est possible de penser qu'ils possèdent peut-être un métalangage plus restreint lié aux notions du conte. Nous voyons, par exemple, que les mots conte et histoire sont les plus souvent mis de l'avant. Le fait que les élèves du Québec ne fassent pas mention du mot conteur, contrairement aux élèves de Guadeloupe, vient peut-être de ce que, dans la culture québécoise, une importance moins grande soit actuellement accordée à la dimension orale du conte, et donc au rôle de conteur. Le Collectif Littorale a d'ailleurs publié en 2011 un recueil faisant part de deux constats importants relativement au conte :

au cœur de notre modernité et de ses mutations bouleversantes, le conte a toujours droit et devoir de parole bien au-delà des nostalgies du bon vieux temps, mais il est lui-même sujet aux mouvements et doit impérativement en tenir compte et se définir au sein de ce qui fonde notre contemporanéité, condition de sa survivance, et sa vivacité est nécessaire (Collectif Littorale, $2011: 10$ ).

Concernant les autres mots apparus dans les réponses à cette question chez les élèves, certains sont liés aux noms de " personnages » et aux « lieux ». Nous n'examinons pas ici en détail car ces deux aspects traités à l'occasion d'autres questions. Néanmoins, on peut déjà souligner que, dans la catégorie "personnages », on retrouve certains noms issus de contes créoles (lapin, cheval), de contes québécois (Rose Latulipe, Diable) ou encore de contes connus (Les trois petits cochons, Le Petit Chaperon rouge, Cendrillon), mais aussi des termes génériques pour désigner des personnages souvent présents dans les contes en général (dragon, monstre, prince, princesse, vieille dame, fille, grand-mère, chevalier, fée, reine, roi). Cela montre que les différents types de personnages constituent un élément important dans la conception du conte chez les élèves interrogés, car ils sont spontanément donnés dans les deux contextes. On peut éventuellement relever que, si les noms des personnages des contes créoles, comme Compère Lapin et Compère Cheval, apparaissent dans les réponses des élèves guadeloupéens au pré-test et au post-test, ils n'apparaissent pas chez les élèves québécois aux deux passations. Le personnage central du conte québécois, Rose Latulipe, quant à lui, apparaît uniquement au post-test tant en Guadeloupe qu'au Québec. On peut également noter que si le nombre de mots faisant référence à des personnages augmente considérablement et passe de 5 à 15 en Guadeloupe, celui-ci diminue légèrement au Québec en passant de 14 à 10.

Concernant les « lieux » cités par les élèves, ceux-ci sont très peu nombreux. On peut relever qu'ils n'apparaissent qu'au post-test pour la Guadeloupe. Il s'agit notamment du mot palais (2 fois), mot qui n'est présent dans aucun des deux contes étudiés en classe. Pour le Québec les mots château ( 1 fois), paysage commun (1 fois) et paysage fantastique (1 fois) sont évoqués uniquement au post-test. 
Concernant les « sentiments » liés au conte, celui qui est le plus fréquent est faire peur (6 fois au total, en prenant en compte le pré-test et le post-test des deux territoires), puis divertir (3 fois), endormir ( 2 fois), alors que tous les autres sentiments n'apparaissent qu'une seule fois (amour, faire rire, faire rêver, émerveiller, réunir pour partager, pleurer, adorer entendre, attachant, plaisir à écouter). On peut aussi relever que si le nombre de mots faisant référence à des sentiments reste identique entre le pré-test et le post-test dans les deux territoires, il est plus élevé en Guadeloupe qu'au Québec (respectivement 8 et 2 au pré-test et au post-test), sachant qu'il y a 20 répondants en Guadeloupe et 15 au Québec.

Concernant les « caractéristiques » du conte, on peut noter que les élèves des deux territoires donnent plus de précisions au post-test qu'au pré-test. En effet, on passe de 9 éléments à 14 éléments en Guadeloupe, et de 9 à 23 éléments au Québec (cf. Annexe 6). On peut dire que les élèves des deux territoires sont capables d'utiliser un vocabulaire plus élaboré en donnant plus de détails sur les caractéristiques du conte à la fin de l'expérimentation. Ceci peut être expliqué par le fait qu'ils ont acquis une connaissance plus experte et un métalangage lié aux caractéristiques du conte plus développé à la suite à l'expérimentation dans les deux territoires.

Au terme de l'analyse des réponses à cette question générale sur le conte, on peut relever que la conception générale du conte des élèves au pré-test est sensiblement identique dans les deux territoires. On note cependant, à la fin de l'expérimentation, un changement conceptuel des élèves de Guadeloupe, du fait que leurs réponses font désormais apparaître la dimension orale et le rôle du conteur, avec un ancrage contextuel plus marqué en lien avec les spécificité du conte créole et sa forte oralité. On peut également relever que les élèves des deux territoires sont capables de donner plus de caractéristiques du conte au post-test qu'au prétest. Ainsi, les élèves des deux territoires développent des connaissances plus expertes sur le conte à la fin de l'expérimentation.

\subsection{Question n5 : «Quels sont les mots et les expressions souvent utilisées dans un conte? "}

Cette question avait pour objectif de sonder les élèves sur leurs connaissances générales et spécifiques des contes en leur demandant de citer quelques expressions qu'ils considéraient comme relevant typiquement des contes, ainsi que des mots que l'on peut trouver fréquemment dans les contes. On peut signaler que 8 élèves de Guadeloupe sur 20 n'ont pas répondu à cette question au pré-test, alors qu'ils y ont tous répondu au post-test. Sur les 15 élèves du Québec, 2 n'ont pas répondu à cette question au pré-test et 3 au post-test. À la suite de l'analyse des réponses, nous avons choisi de distinguer, d'un côté, les expressions, et de l'autre, les mots uniques, en vue d'établir des catégories pour chacun d'entre eux.

Concernant les expressions, nous avons constitué 8 catégories (cf. Annexe 7) et le graphique 2 illustre la fréquence d'apparition de ces catégories au sein des réponses des élèves des deux territoires au pré-test et au post-test. 


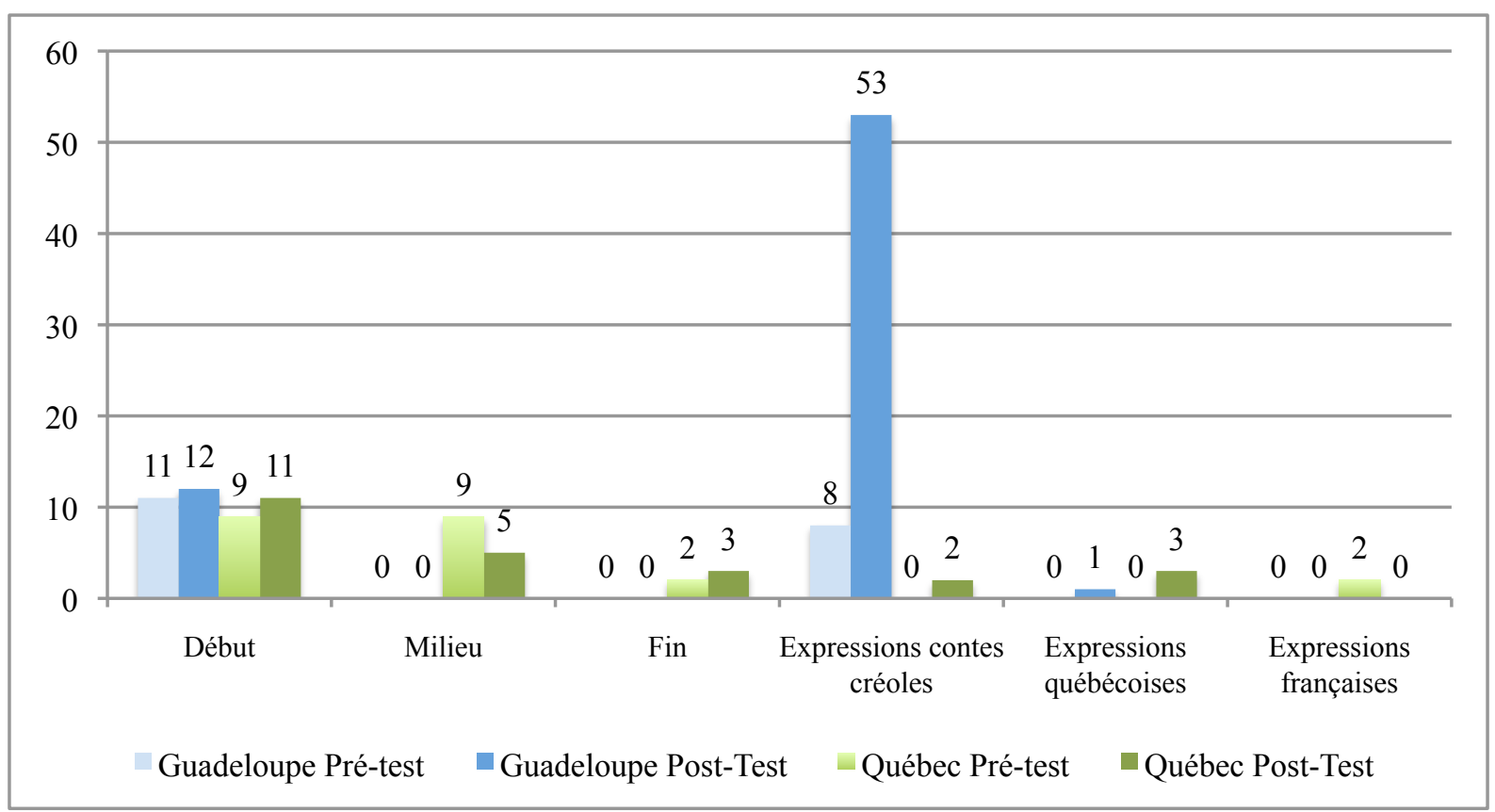

\section{Graphique 2 : Fréquence d'apparition des expressions relatives aux contes}

Les trois premières catégories regroupent des expressions classiques que l'on retrouve dans la plupart des contes européens. Ce sont donc des réponses dites «acontextuelles ». Elles concernent les expressions utilisées généralement pour le « début » d'un conte, comme il était une fois par exemple qui apparait 29 fois (catégorie 1); pour le « milieu », comme tout à coup qui est présent 4 fois (catégorie 2); et pour la fin, comme ils vécurent heureux qui est cité 4 fois (catégorie 3). On peut remarquer que les élèves de la Guadeloupe et du Québec connaissent des expressions utilisées au début des contes et que cette connaissance évolue peu entre le pré-test et le post-test. Par contre, seuls les élèves du Québec proposent des expressions que l'on peut retrouver au milieu et à la fin d'un conte. On peut donc dire qu'ils ont une connaissance un peu plus complète, donc plus experte que celle des élèves de la Guadeloupe concernant les expressions typiques utilisées aux différents moments d'un conte en général. Est-ce lié au fait que les élèves québécois lisent beaucoup de contes ou que les contes québécois utilisent plus fréquemment ce type d'expression ? Est-ce lié à l'écriture de contes en classe et aux mots-clés proposés par leur enseignant? Nous ne pouvons en être certain, mais il s'agit d'une interprétation tout à fait plausible.

Nous avons ensuite relevé trois types d'expression : des expressions spécifiques aux contes créoles (catégorie 4), des expressions non spécifiques au conte relevant d'un français québécois (catégorie 5) et d'un français plus standardisé (catégorie 6). Concernant les expressions spécifiques aux contes créoles, on retrouve Yékrik Yékrak qui apparaît 20 fois au post-test et qui n'était apparue qu'une fois au pré-test. C'est une expression typique des contes créoles qui est généralement employée au début pour capter l'attention du public. En effet, le conteur crie Yékrik et le public doit répondre Yékrak. Pour cette catégorie, on remarque que les élèves de la Guadeloupe possèdent peu d'expressions typiques des contes créoles avant l'expérimentation, alors qu'au post-test, ils ont tous su donner une ou plusieurs expressions créoles typiques des contes guadeloupéens. Ainsi, on peut qualifier leur connaissance à ce niveau comme étant plus contextuelle et experte à la fin de l'expérimentation. Seules deux expressions typiques (Mistikrik Mistikrak et Krik Krak) des contes créoles ont été proposées une seule fois par deux élèves du Québec au post-test, révélant ainsi une connaissance enrichie et multicontextuelle. 
Concernant les expressions québécoises relevées (catégorie 5), il ne s'agit pas d'expressions typiques des contes québécois, mais plutôt d'expressions courantes en français utilisées au Québec comme tire-toi une bûche, qui signifie prends-toi une chaise pour t'asseoir. Ces expressions ne sont pas nombreuses chez les élèves du Québec (3 au total), et on peut signaler qu'un élève de Guadeloupe en a proposé une seule au post-test. Concernant les expressions françaises plutôt courantes et non d'expressions relatives au conte (catégorie 6), les expressions chercher une aiguille dans une botte de foin et dormir comme une bûche n'apparaissent qu'une seule fois. Elles sont en faible nombre et sont présentes uniquement au pré-test au Québec. Le fait qu'elles ne réapparaissent pas au post-test peut éventuellement signifier que les élèves font maintenant la distinction entre des expressions utilisées dans le langage courant et celles plus spécifiques au conte, ce qui pourrait s'apparenter à une connaissance plus experte.

La catégorie 7 regroupe des expressions que nous n'avons pas su classer comme cayer des bras ou Il avait un air de leveuf. Elles sont en faible nombre et leur signification n'a pas pu être trouvée. Enfin la dernière catégorie regroupe des réponses d'élèves qui dépassent la simple citation d'expressions en mettant l'accent sur leur fonction (catégorie 8), comme garder ou attirer l'attention, débuter. Ces réponses en très faible nombre n'apparaissent qu'au post-test tant en Guadeloupe qu'au Québec. Elles montrent que quelques élèves possèdent désormais une connaissance plus complète et experte du rôle des expressions dans ce genre littéraire. Au terme de cette analyse proposée sur les expressions, on peut noter que les élèves de Guadeloupe sont passés d'une connaissance acontextuelle et spontanée à une connaissance plus experte et contextuelle tandis que les élèves du Québec possèdent une connaissance plus experte et acontextuelle au départ, et que celle-ci évolue peu à la fin de l'expérimentation.

Concernant les mots uniques relatifs aux contes que les élèves des deux territoires proposent, ceux-ci ne sont pas nombreux (cf. Annexe 8). Le graphique 3 illustre ces réponses.

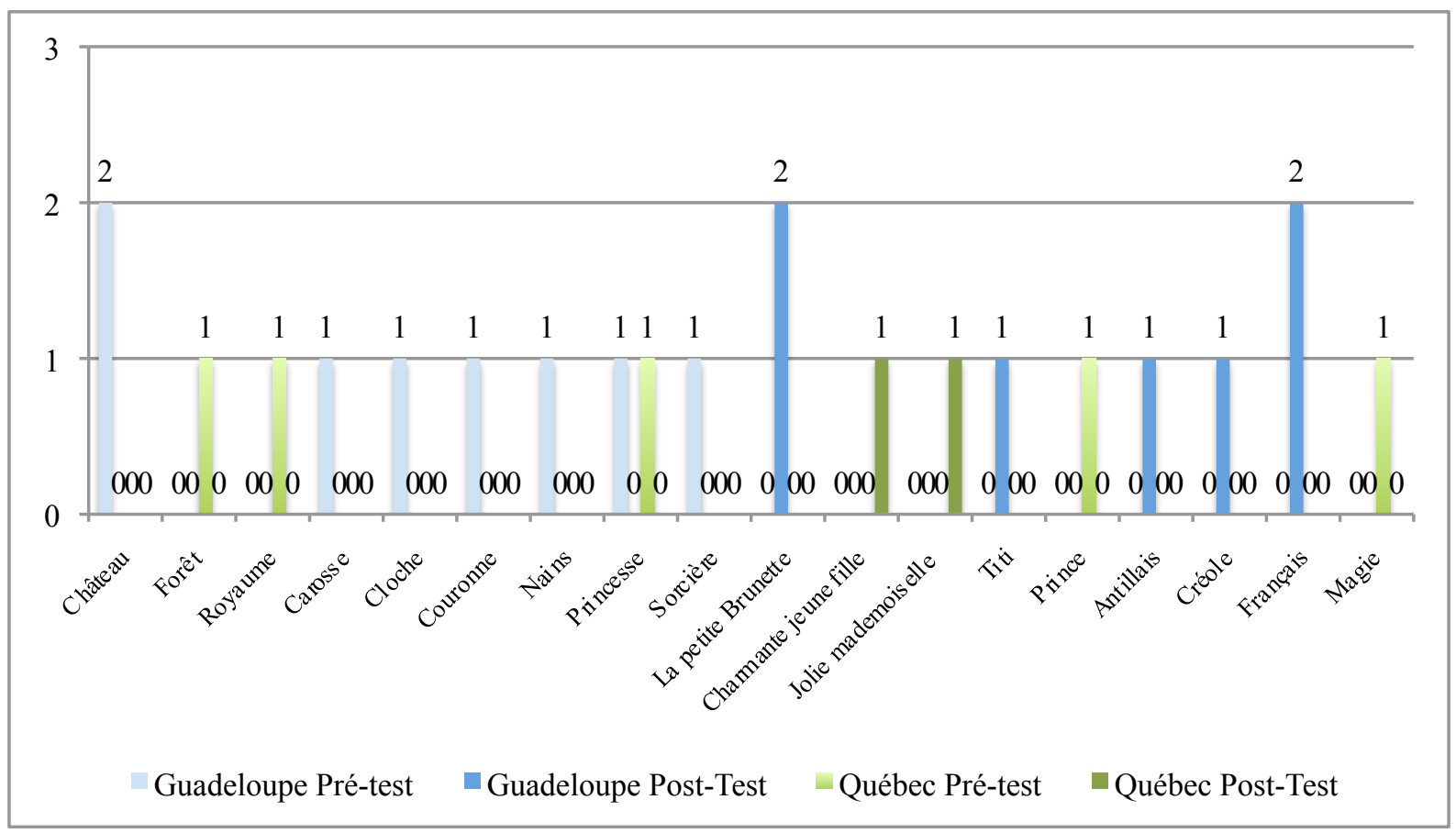

Graphique 3 : Fréquence d'apparition des mots relatifs aux contes 
On peut relever des mots relatifs aux «lieux» (château, forêt, royaume), aux " objets" (carrosse, cloche, couronne), aux "personnages" (nains, princesse, sorcière, la petite brunette, une charmante jeune fille, une jolie demoiselle, titi, prince), aux "territoires" (créole, antillais, français) et "autres" (magie). Tous ces mots n'apparaissent qu'une ou deux fois seulement. On peut souligner l'apparition des personnages principaux du conte québécois dans les réponses de deux élèves de Guadeloupe au post-test, et l'apparition de trois mots désignant des territoires (antillais, créole, français) au post-test chez quatre élèves de Guadeloupe qui pourrait laisser supposer que ces élèves nuancent leur réponse sur le plan culturel et ont donc une connaissance peut-être plus multicontextuelle.

\subsection{Question $n^{\circ} 6$ : «Quels sont les personnages que l'on retrouve souvent dans un conte ?»}

Pour répondre à cette question, les élèves devaient proposer des personnages qu'ils connaissaient et qu'ils associaient aux contes. Tous les élèves du Québec ont fait des propositions de personnages au pré-test et au post-test, alors que trois élèves de Guadeloupe n'ont pas répondu à cette question au pré-test, mais tous ont fait des propositions lors du posttest. À la suite de l'analyse des réponses données par les élèves à cette question (cf. Annexe 9), nous avons constitué 7 catégories. La première catégorie rassemble des personnages typiques du conte créole étudié en classe par les élèves de Guadeloupe (ex. Compère Lapin), et des contes créoles en général, même s'ils sont absents du conte étudié (ex. Ti Jan). La deuxième catégorie regroupe les personnages du conte québécois étudié en classe par les élèves du Québec (ex. Rose Latulipe). La troisième catégorie est constituée de personnages connus de contes célèbres qui ont souvent fait l'objet de films et de dessins animés (ex. Cendrillon). Si les trois premières catégories sont des propositions de noms de personnages, les trois catégories suivantes sont plutôt des termes génériques. La quatrième catégorie propose des types de personnages humains que l'on peut retrouver dans un conte (ex. les princesses). La cinquième catégorie regroupe des propositions d'animaux susceptibles d'apparaître dans un conte (ex. le loup). La sixième catégorie est constituée de propositions de créatures fantastiques que l'on peut trouver dans un conte (ex. le dragon). Enfin, la septième et dernière catégorie rassemble de mots qui définissent des caractéristiques des personnages de conte (ex. les méchants). Le graphique 4 illustre la fréquence d'apparition des mots proposés par les élèves des deux classes pour l'ensemble de ces catégories.

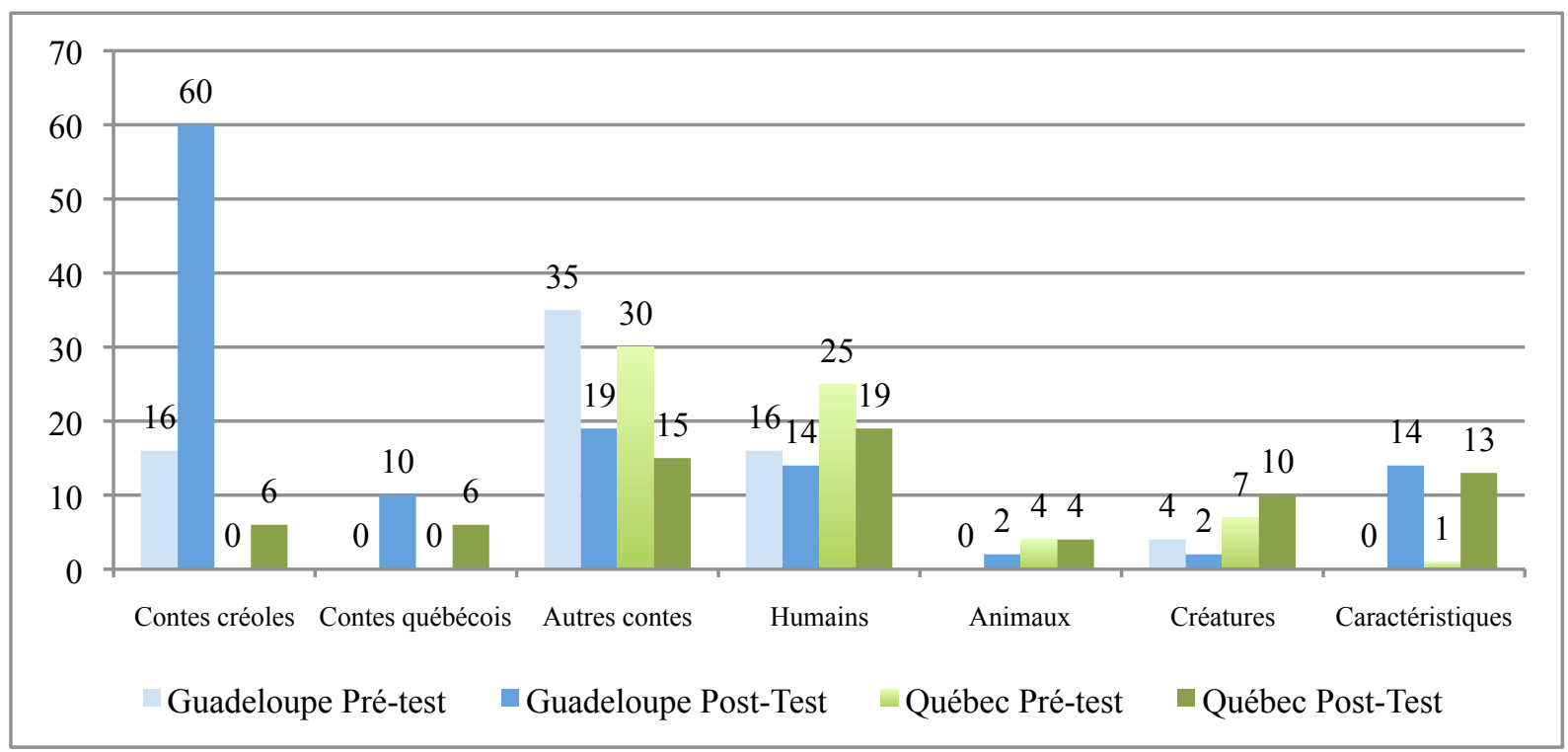

Graphique 4 : Fréquence d'apparition des personnages relatifs aux contes 
Concernant les élèves de Guadeloupe, on peut observer que le nombre de personnages qu'ils proposent dans la catégorie « contes créoles » subit une augmentation considérable (on passe de 16 à 60 noms de personnages au total pour l'ensemble de la classe), ce qui peut être interprété comme une connaissance contextuelle plus experte de ces élèves. Les élèves du Québec proposent également quelques noms de personnages de contes créoles au post-test. Cela montre qu'ils ont enrichi leurs connaissances sur les personnages de contes en proposant des noms de personnages de contes créoles, et que leur connaissance devient multicontextuelle. Pour la catégorie " conte québécois », on peut observer que les élèves des deux territoires proposent quelques exemples, et ce, uniquement au post-test. L'expérimentation a donc permis aux élèves des deux territoires d'avoir une connaissance plus contextuelle, mais aussi multicontextuelle. Concernant les noms de personnages de contes classiques en général, on peut observer que, si le nombre de noms diminue entre le prétest et le post-test pour les deux classes, cette catégorie reste présente et témoigne d'une connaissance acontextuelle initiale qui est toujours présente en fin d'expérimentation. Concernant les types d' " humains », d' " animaux et de " créatures », on ne note pas de différences importantes entre le pré-test et le post-test et entre les territoires. Le nombre de type d'humains est cependant plus élevé que celui d'animaux et de créatures. Enfin, on peut relever que les élèves des deux territoires proposent des caractéristiques des personnages au post-test, ce qui montre une connaissance plus experte, plus complète et plus fine des personnages de contes de façon générale. Ainsi, on peut dire que les élèves de Guadeloupe sont passés d'une connaissance spontanée contextuelle et acontextuelle à une connaissance multicontextuelle et experte. Quant aux élèves du Québec, ils sont passés d'une connaissance spontanée acontextuelle à une connaissance multicontextuelle et experte.

\subsection{Question $n^{\circ 7}$ : «Dans quel type de lieux se passent généralement les contes ?»}

Cette question visait à identifier les différents types de lieux qui structurent l'univers du conte chez les élèves participant à l'expérimentation. Au pré-test, tous les élèves du Québec ont fait des propositions, quatre élèves de Guadeloupe n'ont pas répondu à cette question et une réponse a été considérée comme " hors sujet». En effet, cette dernière a été rejetée car l'élève a donné des lieux où on lisait les contes (tels que l'école, la chambre ou les médiathèques), et non pas les lieux où se déroulaient les contes. Au post-test, tous les participants des deux territoires ont suggéré des exemples de lieux représentatifs du conte pour eux. Le graphique 5 illustre la fréquence des noms de lieux proposés pour cette réponse.

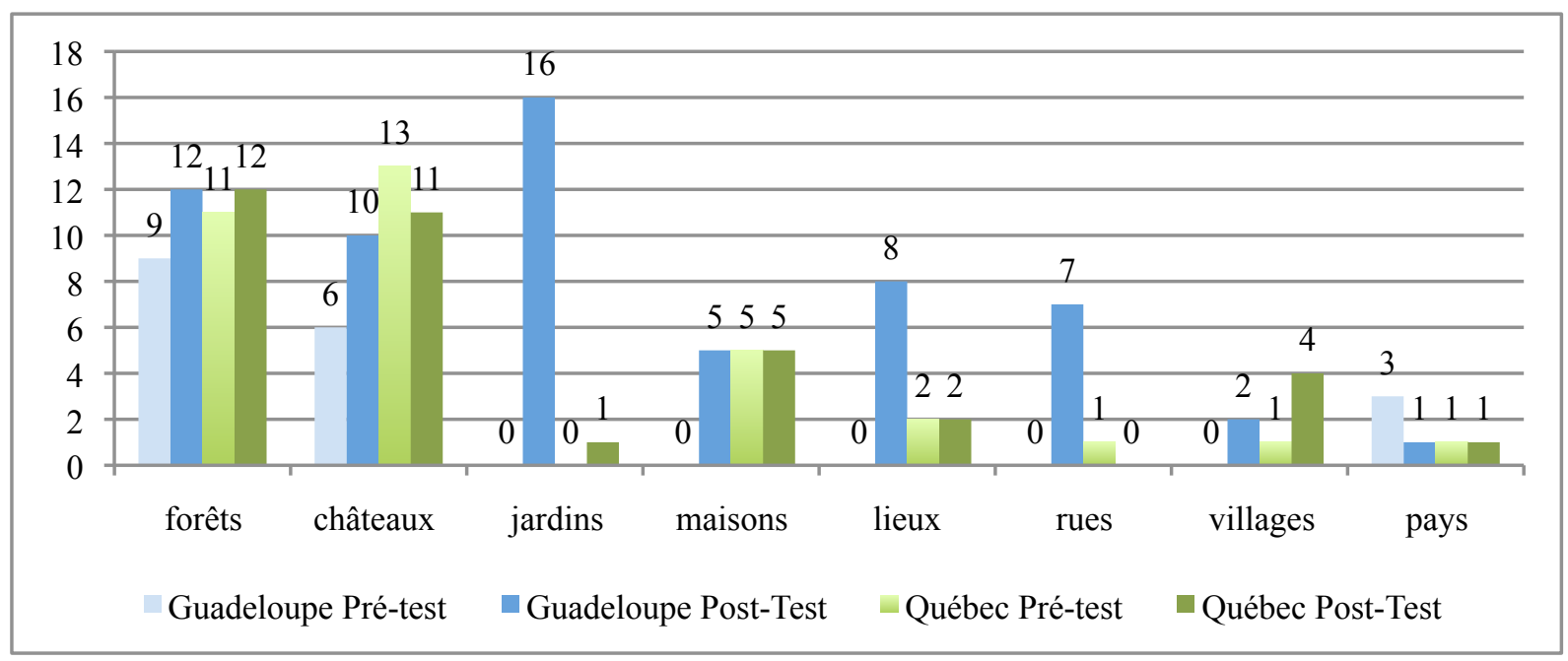

Graphique 5 : Fréquence d'apparition des types de lieux 
En fonction de la fréquence des noms de lieux dans les réponses des élèves à cette question (cf. Annexe 10), deux lieux typiques d'un conte ressortent très largement au final : forêts et châteaux (respectivement 44 fois et 40 fois, si l'on fait la somme de toutes les réponses des élèves des deux territoires au pré-test et au post-test). Ces deux lieux peuvent être considérés comme des lieux typiques, pour les élèves interrogés, dans lesquels peuvent se dérouler un conte et être rattachés à une connaissance acontextuelle et spontanée des contes. Présents au pré-test comme au post-test, et ce, sur les deux territoires, on note par ailleurs qu'il n'y a pas de différence quantitative importante en fonction du moment de passation du test. Ensuite quatre autres lieux apparaissent, dont deux sont présents dans le conte créole étudié (jardins et rues) et deux autres dans le conte québécois étudié (maisons et villages). Ces quatre mots peuvent être rattachés à une connaissance contextuelle des élèves de chaque territoire.

En Guadeloupe, on peut observer que les mots jardins et rues ne sont pas présents dans les réponses des élèves au pré-test et qu'ils apparaissent de manière importante lors du post-test ( 16 fois le mot jardins et 7 fois le mot rues). Il est notable qu'une grande partie des élèves en Guadeloupe ont donné l'exemple du jardin au post-test en montrant ainsi une connaissance plus contextuelle des lieux possibles dans lesquels se déroulent des contes. De plus, les mots maisons et villages, présents dans le conte québécois apparaissent aussi dans les réponses des élèves guadeloupéens au post-test (respectivement 5 fois et 2 fois) alors qu'ils n'apparaissaient pas au pré-test. On peut supposer qu'ils ont pris en considération les lieux du conte québécois étudié par leurs homologues dans leurs réponses, et donc qu'ils ont une connaissance multicontextuelle, puisqu'au post-test, certains proposent des lieux des contes classiques, des contes créoles et québécois étudiés.

Au Québec, les élèves proposent un peu plus le mot villages au post-test. On passe de 1 fois à 4 fois, tandis que le mot maisons apparait 5 fois au pré-test et au post-test. On peut relever l'apparition une seule fois du mot jardins dans les réponses des élèves du Québec au post-test. On peut considérer que si les élèves du Québec interrogés ont initialement une connaissance acontextuelle des lieux des contes, ils augmentent un peu leurs propositions à la suite de l'étude du conte québécois et acquièrent une connaissance plus contextuelle. Par contre, les lieux du conte créole étudié n'apparaissent que de manière anecdotique dans leur réponse, n'attestant pas d'une connaissance multicontextuelle.

En outre, en tenant compte des adjectifs que les élèves ont apposés aux différents noms de lieux dans leur réponse en leur attribuant des caractéristiques qualitatives, comme : forêts enchantées et magiques; châteaux habités et magiques ; maisons invivables, hantées, vieilles, de campagne et de luxe, on peut noter un certain niveau d'expertise chez ces élèves et la distinction entre des lieux imaginaires et des lieux réels. Le graphique 6 illustre les réponses qui ont été obtenues au moins deux fois. 


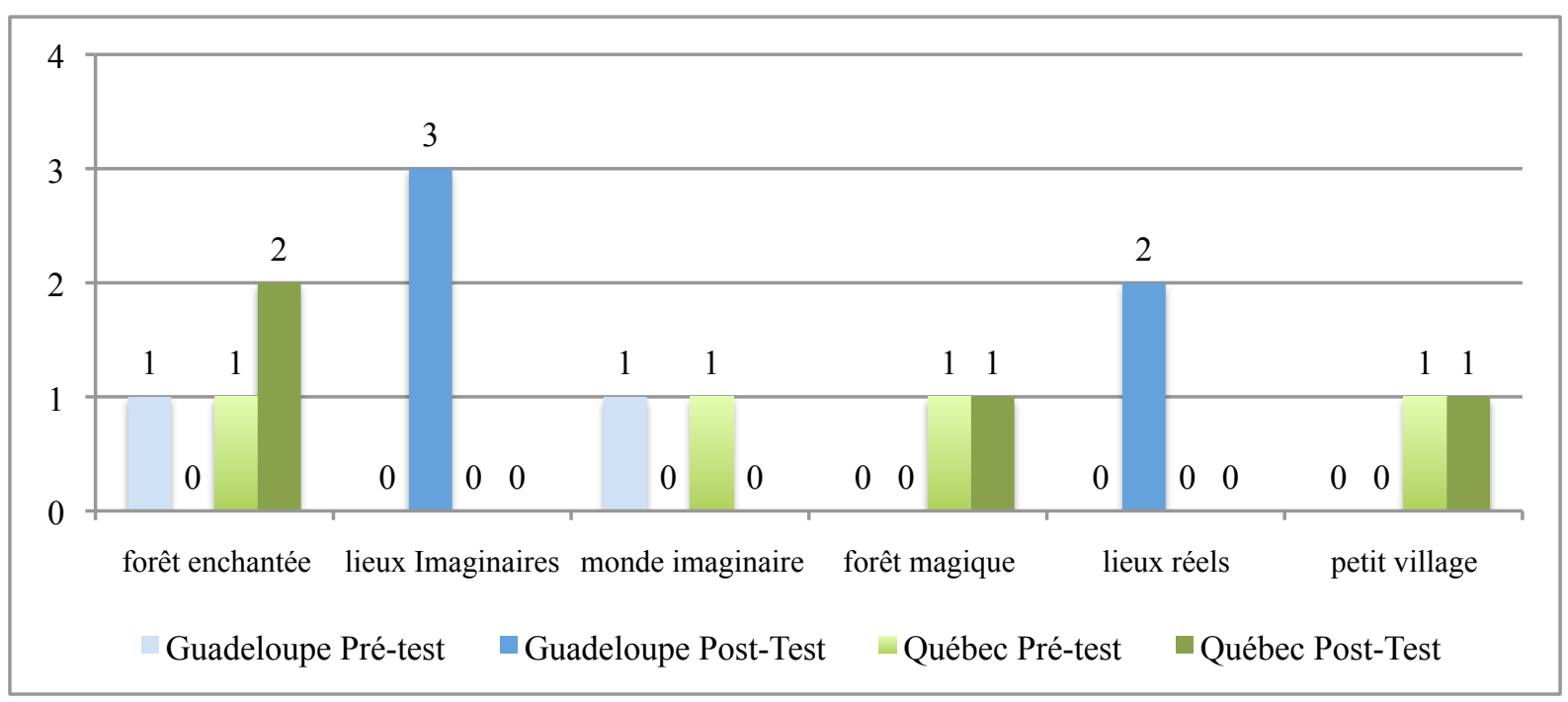

Graphique 6 : Fréquence d'apparition des types de lieux avec des adjectifs

Ces lieux, qu'ils soient mythiques ou réels, constituent un espace symbolique qui relie souvent les moments clés des emplacements et des déplacements des personnages dans une histoire. En résumé, les résultats à cette question nous indiquent que les participants à notre expérimentation élisent au départ plutôt des éléments du réel, même si souvent les lieux réels pour le lecteur, peuvent se mêler à l'imaginaire. Par exemple, la forêt, lieu du « réel », peut par ailleurs être un lieu d'exploration et d'imagination, et être associé dans un conte, comme à un lieu où se nouent des intrigues, caractérisées par des rencontres, belles, magiques, dangereuses, etc. De ce fait, il semble ainsi que, durant cette itération, les élèves ont eu l'occasion de s'approprier des savoirs contextuels et d'élargir leurs connaissances sur la notion de lieux dans un conte.

\section{Analyse du niveau d'expertise et de contextualité des réponses des élèves}

Cette expérimentation avait comme objectif de faire collaborer deux classes, l'une au Québec et l'autre en Guadeloupe, autour d'un objet d'enseignement, le conte. Elle s'est déroulée sur plus d'un mois et les élèves ont étudié chacun un conte issu de leur environnement culturel (Rose Latulipe pour le Québec et Compère Zamba voulait tromper Compère Lapin pour la Guadeloupe). Chacune des deux classes a étudié son conte respectif et des temps de travail et d'échanges entre des groupes d'élèves sur une même thématique (aussi appelé équipe-miroir) ont été planifiés. Cinq équipes-miroirs ont été constituées et ont travaillé sur les cinq thématiques suivantes: les expressions et le lexique, les personnages, les lieux, le schéma narratif et les références culturelles. Avant et après l'expérimentation, tous les élèves des deux classes participant à l'expérimentation ont eu à compléter un questionnaire sur le conte en général afin d'évaluer leurs connaissances initiales et finales. Nous avons choisi d'analyser dans le cadre de cet article leurs réponses aux quatre questions suivantes :

- Question $n^{\circ} 3$ : Pour toi, qu'est-ce qu'un conte ? Peux-tu expliquer ce qu'est un conte pour toi en quelques phrases?

- Question $n^{\circ} 5$ : Quels sont les mots et les expressions souvent utilisées dans un conte ? Peux-tu donner quelques exemples de mots et d'expressions que l'on retrouve souvent dans un conte?

- Question $n^{\circ} 6$ : Quels sont les personnages que l'on retrouve souvent dans un conte ? Peux-tu donner quelques exemples de noms de personnages de contes que tu connais?

- Question $n^{\circ} 7$ : Dans quels types de lieux se passent généralement les contes ? Peux-tu donner quelques exemples de lieux dans lesquels se déroulent des contes ? 
On peut observer que, pour chaque question posée, quelques élèves en Guadeloupe ne répondaient pas lors du pré-test alors qu'ils ont répondu à toutes les questions lors du posttest. Ce résultat peut être interprété comme un manque de connaissances initiales ou, potentiellement, comme une peur de se tromper qui a été "dépassée » à la fin de l'expérimentation. Concernant les élèves du Québec, ils ont tous répondu à chaque question tant au pré-test qu'au post-test. L'hypothèse qui pourrait être faite, quant à ces divergences, serait que les élèves québécois avaient peut-être une connaissance plus approfondie du conte au départ que leurs homologues guadeloupéens.

Afin d'évaluer les réponses des élèves à chaque question, nous avons choisi d'utiliser deux échelles de notation, la première évaluant le niveau de contextualité de la réponse, et la seconde le niveau d'expertise. Concernant le niveau de contextualité, nous avons identifié quatre catégories. Nous avons qualifié de connaissance acontextuelle, les réponses étrangères au contexte culturel de l'élève. Les réponses dites contextuelles apportent des éléments en lien avec les contextes culturels proches des élèves et du conte étudié. Les réponses bicontextuelles correspondent à des connaissances du conte appartenant à deux contextes différents, soit du conte en général et du conte étudié en classe, soit des deux contes étudiés. Enfin, les réponses dites multicontextuelles font apparaître des éléments du conte en général, et des deux contes étudiés en classe. Il s'agit donc de connaissances issues de trois contextes différents (général, guadeloupéen et québécois).

Concernant le niveau d'expertise, plusieurs éléments ont été pris en considération en fonction des questions. Le nombre d'éléments, la précision des informations, la diversité des réponses ont constitué des indicateurs pour classer les réponses selon trois niveaux. Le niveau spontané regroupe des réponses simples et connues de tous, avec peu d'éléments et de précision. Le niveau confirmé rassemble des réponses qui présentent plus d'informations et de précisions. Enfin le niveau expert réunit des réponses qui témoignent d'une connaissance riche, fournie, précise et diversifiée sur le conte faisant même apparaître une capacité de catégorisation fine.

Le tableau 2 propose une classification générale des réponses des élèves des deux territoires aux deux moments d'évaluation. Nous avons choisi de faire apparaître uniquement les deux tendances générales les plus quantitativement représentatives en indiquant entre parenthèses le nombre de types de réponses relevées chez les élèves (pour plus de précisions, voir les graphiques illustrant l'ensemble des réponses aux quatre questions posées en Annexe 11). À titre de rappel, les élèves de la Guadeloupe ayant participé à l'étude sont au nombre de 20 et ceux du Québec au nombre de 15. Les chiffres présentés dans le tableau 2 ci-dessous sont donc à considérer en fonction du nombre d'élèves pour chacune des classes. 


\begin{tabular}{|c|c|c|c|c|c|}
\hline & \multicolumn{2}{|c|}{ Guadeloupe } & \multicolumn{2}{|c|}{ Québec } \\
\hline & & Pré-test & Post-test & Pré-test & Post-test \\
\hline \multirow{2}{*}{$\begin{array}{l}\text { Question } n^{\circ} 3 \\
\text { (conte) }\end{array}$} & Contextualité & $\begin{array}{c}\text { acontextuelle (11) } \\
\text { contextuelle (3) }\end{array}$ & $\begin{array}{l}\text { acontextuelle (10) } \\
\text { contextuelle (7) }\end{array}$ & $\begin{array}{c}\text { acontextuelle (12) } \\
\text { contextuelle (3) }\end{array}$ & $\begin{array}{l}\text { bicontextuelle (7) } \\
\text { acontextuelle (5) }\end{array}$ \\
\hline & Expertise & $\begin{array}{l}\text { spontanée (11) } \\
\text { expert (3) }\end{array}$ & $\begin{array}{l}\text { spontanée (9) } \\
\text { confirmée (6) }\end{array}$ & $\begin{array}{l}\text { spontanée (10) } \\
\text { confirmée (5) }\end{array}$ & $\begin{array}{l}\text { confirmée (12) } \\
\text { spontanée (2) }\end{array}$ \\
\hline \multirow{2}{*}{$\begin{array}{l}\text { Question n5 } \\
\text { (mots et } \\
\text { expressions) }\end{array}$} & Contextualité & $\begin{array}{l}\text { acontextuelle (8) } \\
\text { contextuelle (2) }\end{array}$ & $\begin{array}{l}\text { contextuelle (10) } \\
\text { bicontextuelle (9) }\end{array}$ & acontextuelle (9) & $\begin{array}{c}\text { acontextuelle (10) } \\
\text { contextuelle (1) }\end{array}$ \\
\hline & Expertise & $\begin{array}{l}\text { spontanée (8) } \\
\text { confirmée (2) }\end{array}$ & $\begin{array}{l}\text { experte (10) } \\
\text { confirmée }(9)\end{array}$ & $\begin{array}{l}\text { spontanée (5) } \\
\text { confirmée (4) }\end{array}$ & $\begin{array}{l}\text { spontanée (7) } \\
\text { experte (2) }\end{array}$ \\
\hline \multirow{2}{*}{$\begin{array}{l}\text { Question } n^{\circ} 6 \\
\text { (personnages) }\end{array}$} & Contextualité & $\begin{array}{l}\text { acontextuelle (7) } \\
\text { contextuelle (7) }\end{array}$ & $\begin{array}{l}\text { bicontextuelle (9) } \\
\text { multicontextuelle } \\
(5)\end{array}$ & acontextuelle (15) & $\begin{array}{c}\text { acontextuelle (8) } \\
\text { bicontextuelle (5) }\end{array}$ \\
\hline & Expertise & $\begin{array}{l}\text { spontanée (9) } \\
\text { confirmée (8) }\end{array}$ & $\begin{array}{l}\text { confirmée (11) } \\
\text { spontanée (8) }\end{array}$ & $\begin{array}{l}\text { spontanée (7) } \\
\text { confirmée (7) }\end{array}$ & $\begin{array}{l}\text { spontanée (10) } \\
\text { confirmée (4) }\end{array}$ \\
\hline \multirow{2}{*}{$\begin{array}{l}\text { Question n'7 } \\
\text { (lieux) }\end{array}$} & Contextualité & $\begin{array}{c}\text { acontextuelle (11) } \\
\text { contextuelle (3) }\end{array}$ & $\begin{array}{c}\text { bicontextuelle (11) } \\
\text { multicontextuelle } \\
(7)\end{array}$ & $\begin{array}{l}\text { acontextuelle (13) } \\
\text { bicontextuelle (2) }\end{array}$ & $\begin{array}{l}\text { acontextuelle (7) } \\
\text { bicontextuelle (7) }\end{array}$ \\
\hline & Expertise & $\begin{array}{l}\text { spontanée (11) } \\
\text { confirmée (4) }\end{array}$ & $\begin{array}{l}\text { confirmée (11) } \\
\text { experte (6) }\end{array}$ & $\begin{array}{l}\text { confirmée (12) } \\
\text { spontanée (3) }\end{array}$ & $\begin{array}{l}\text { confirmée (9) } \\
\text { spontanée (6) }\end{array}$ \\
\hline
\end{tabular}

Tableau 2 : Tendances générales des types de connaissances en fonction des questions, des lieux et des moments d'évaluation

Concernant le niveau de contextualité des réponses, il ressort de l'analyse des résultats que la majorité des élèves pour les quatre questions posées mobilise des connaissances acontextuelles au pré-test. Par exemple, pour la question $\mathrm{n}^{\circ} 3$, un élève de Guadeloupe répond : un conte, c'est une histoire pour les enfants; un autre au Québec : un conte est une fausse histoire souvent on la raconte à l'enfant. Certaines réponses au pré-test en Guadeloupe montrent que les élèves mobilisent aussi des connaissances bicontextuelles pour chacune des questions. Par exemple, pour la question $\mathrm{n}^{\circ} 5$, un élève propose la réponse suivante : il était une fois, Yékrik Yékrak. Au Québec, seules deux questions font apparaître des réponses attestant de connaissances de type contextuel (pour la question $\mathrm{n}^{\circ} 3$ : une histoire de princesse et de chevalier) ou bicontextuel (pour la question $\mathrm{n}^{\circ} 7$ : dans les forêts, dans un château, dans un petit village lointain, dans une maison hantée).

$\mathrm{Au}$ post-test en Guadeloupe, on peut observer une transformation des conceptions des élèves dans la mesure où les réponses deviennent majoritairement soit contextuelles (par exemple, pour la question $\mathrm{n}^{\circ} 6$, un élève répond : Kompè Lapin, Kompè Zamba), soit bicontextuelles (pour la question $n^{\circ} 6$, un élève répond : Kompè Lapin, Kompè Zamba et le Diable; un autre propose : Kompè Lapin, Kompè Zamba, Blanche neige, le Chaperon rouge, Cendrillon, la Belle et la Bête, ti Sapotille, ti Désodié), voire multicontextuelles (pour la question n6, un élève répond : Kompè Lapin, Kompè Zamba, Rose Latulipe, le Diable, Pinoquio, la reine des neiges, Vayana, Judy dans Zootopie). Au post-test au Québec, on peut également observer une transformation des conceptions des élèves dans la mesure où les réponses deviennent majoritairement soit acontextuelles (par exemple, pour la question $\mathrm{n}^{\circ} 7$, un élève répond : forêt enchantée, château), soit bicontextuelles (pour la question $\mathrm{n}^{\circ} 7$, un élève répond: dans un village, dans la forêt; un autre propose : les château, dans la forêt, palais et maisons), voire 
multicontextuelles (pour la question $\mathrm{n}^{\circ} 7$, un élève répond: forêt, jardin, château, village). Cela montre que les élèves des deux territoires ont pu renforcer leurs connaissances à la fois en lien avec le conte étudié issu de leur contexte et celui étudié par l'autre classe.

Les élèves de Guadeloupe ont conservé uniquement une connaissance majoritairement acontextuelle à la question $\mathrm{n}^{\circ} 3$ (un élève répond : un livre, une histoire), alors que les élèves du Québec ont conservé une connaissance plus acontextuelle aux questions $\mathrm{n}^{\circ} 5$ (un élève répond : il était une fois), $\mathrm{n}^{\circ} 6$ (un élève répond : la petite sirène, Raiponce, Blanche neige, la belle au bois dormant) et $\mathrm{n}^{\circ} 7$ (un élève répond : château, forêt). On peut expliquer ce résultat par le fait que le conte choisi pour l'expérimentation au Québec possède les mêmes caractéristiques que celles des contes classiques généralement rencontrés par les élèves québécois. En effet, ceux-ci respectent notamment la structure du schéma narratif. Quant aux contes créoles, ils possèdent des caractéristiques différentes des contes classiques. Cet élément sera donc à prendre en considération dans la perspective de futures itérations confrontant des contextes sur cet objet d'enseignement.

Concernant le niveau d'expertise des réponses au pré-test, on observe que toutes les réponses des élèves aux quatre questions sont d'un niveau spontané dans les deux territoires, sauf pour la question $\mathrm{n}^{\circ} 7$ où les élèves du Québec, dès le pré-test possède une connaissance majoritairement d'un niveau confirmé (un élève répond : dans un pays imaginaire, dans des maisons invivables (histoire triste), dans un château habité). Pour cette question portant sur les lieux, les élèves du Québec proposent un nombre de lieux déjà important au pré-test (un élève répond: dans les forêts, dans un château, dans un petit village lointain, dans une maison hantée) et ils distinguent des lieux réels des lieux imaginaires (un élève répond : à l'école, dans l'espace, dans une maison, dans la rue, dans un monde imaginaire), ce qui n'est pas le cas de leurs homologues guadeloupéens. On peut souligner également que le nombre de réponses des élèves de Guadeloupe au pré-test à la question $\mathrm{n}^{\circ} 6$ portant sur les personnages révèle une connaissance confirmée et les élèves proposent déjà, avant même l'expérimentation, des personnages connus des contes créoles (un élève répond : la reine, le chevalier, le prince, un château, Kompè Zamba, Kompè Chouval, Kompè Lapen, Kompè Taureau). Ensuite, on peut noter qu'au post-test, la quasi-totalité des réponses dénote un niveau d'expertise plus élevé de type confirmé (par exemple, à la question $n^{\circ} 6$, un élève en Guadeloupe répond : Konpè Lapin, Konpè Zamba, Ti Sapotille, Soukounyan, la diablesse, bèt a man ibè, volant, les princesses, les princes; et un élève au Québec répond : des princesses comme Cendrillon, belle et on retrouve aussi des méchants comme le diable dans Rose Tulipe et le loup dans les trois petits cochons), voire expert (par exemple, à la question $\mathrm{n}^{\circ} 5$, un élève en Guadeloupe répond : dans les conte on peut utiliser des expressions comme Yekrik Yekrak, Yemistikrik Yemistikrak, Est-ce que la cour dort? Non. La cour ne dort pas. C'est Isidor qui dort sur un oreiller en or. Pour deux sous d'or; et un élève au Québec répond : il était une fois, il y a bien longtemps pour débuter, Mistikrik mistikrak pour garder l'attention). Cela montre un effet positif de l'expérimentation sur la qualité des réponses. La majorité des élèves en Guadeloupe conserve un niveau spontané pour la question $\mathrm{n}^{\circ} 3$ (un élève répond : c'est une histoire inventée), et au Québec pour les questions $\mathrm{n}^{\circ} 5$ (un élève répond : c'était une fois, depuis ce temps) et $\mathrm{n}^{\circ} 6$ (un élève répond : Le père Noël, Blanche neige, la fée des dents).

On peut noter que l'évolution des conceptions des élèves du Québec est moindre que celles des élèves de la Guadeloupe en général (cf. Annexe 11). Nous expliquons cela en partie par le fait que les spécificités du conte québécois sont peut-être plus proches de celles des contes classiques et connus de toutes et tous, alors que celles du conte guadeloupéen sont peut-être plus spécifiques, originales et distinctes des contes classiques. Ainsi, dans la construction de 
scénarios pédagogiques reposant sur la confrontation de contextes, il semble important de pouvoir tenir compte des écarts entre les conceptions initiales et spontanées des personnes issues de deux contextes différents. Il s'agit de choisir des objets de contextes particuliers qui diffèrent considérablement des conceptions initiales des élèves afin que la confrontation des contextes puisse enrichir leurs conceptions respectives. Dans le cadre de cette étude, le choix du conte québécois « Rose Latulipe » n'était peut-être pas assez éloigné des contes classiques, alors que c'était plus le cas pour le conte guadeloupéen.

Ainsi, l'évaluation de la contextualité et de l'expertise des réponses données par les élèves des deux territoires révèle un niveau plus élevé au post-test qu'au pré-test, ce qui confirme que la création d'un scénario pédagogique susceptible de produire des effets de contexte (Delcroix, Forissier et Anciaux, 2013) entre les élèves de deux classes de deux contextes différents sur un objet d'enseignement particulier enrichit les conceptions des élèves des deux contextes.

\section{Conclusion}

D'un point de vue didactique, les premières analyses résultant des données recueillies dans le cadre de l'itération langue, valident en partie les conclusions d'expérimentations déjà réalisées, notamment dans le cadre des sciences de la vie et de la terre (Forissier, 2015), qui avancent l'idée que la conception d'un scénario pédagogique basé sur des effets de contextes peut favoriser les apprentissages et enrichir les conceptions des apprenants. L'étude d'un même objet par confrontation de contextes différents semble pertinente et permet d'accroître les connaissances des élèves sur l'objet en question, en leur permettant de passer de connaissances acontextuelles et spontanée (uniquement liées à un environnement culturel très généralisé) à des connaissances soit contextuelles (uniquement liées à leur propre contexte et à l'étude du conte en classe), soit bicontextuelles (liées à leur contexte et à celui de l'autre contexte, ou de leur contexte et de l'environnement culturel très général et commun), voire à des connaissances multicontextuelles (liées à l'environnement culturel général, à leur propre environnement et à celui des élèves de l'autre territoire). Cette approche permet ainsi aux élèves de déceler ce qui relève pleinement de la notion à l'étude, tout en percevant comment cet objet revêt des caractéristiques spécifiques en fonction du contexte où il est étudié. De fait, la démarche promeut également une évolution des conceptions de spontanées à expertes. Il est fondamental d'insister sur le postulat initial de la recherche qui repose sur le fait que la confrontation des contextes, pour être efficace, ne se fait pas de façon «artificielle» (présentation de contextes différents par l'enseignant) mais s'ancre dans les réalités contrastées des élèves qui s'inscrivent ainsi dans une démarche d'investigation, particulièrement motivante où tous les points de vue sont possibles.

\section{Références bibliographiques}

Adam, J.-M. (1992). Les textes : Types et prototypes. Paris : Nathan.

Aubert de Gaspé, P. (fils) (2006). La Légende de Rose Latulipe. Le Chercheur de trésor ou l'influence d'un livre. Montréal : Bibliothèque et archives nationales du Québec.

Arizpe, E. et Styles, M. (2016). Children Reading Picturebooks. Interpreting visual texts $\left(2^{\mathrm{e}}\right.$ éd). Londres : Routledge

Bardin, L. (2007). L'analyse de contenu. Paris : PUF.

Bigot, D. (2011). De la norme grammaticale du français parlé au Québec. Arborescences: revue d'études françaises, 1, 1-18.

Bettelheim, B. (1976). Psychanalyse des Contes de Fées. Paris : Editions Robert Laffont.

Boimare, (1992). Lire les mythes pour guérir la peur d'apprendre. Cahiers pédagogiques, 
« La Motivation ».

Bourdeau, J. (2017). The DBR methodology for the study of context in learning. Communication présentée International and Interdisciplinary Conference on Modeling and Using Context.

Césaire, I. (1981). “Littérature orale et contes." L'historial antillais, Guadeloupe et Martinique. Des Îles aux homes. Tome 1. Point-à-Pitre : Dajani Editions. 479-490.

Collectif Littorale (2011). Le conte: témoin du temps, observateur du présent. Montréal : Planète Rebelle.

Combaret du Brès, M. de et Saubrenat, J. (trad.) (1981). Le Roman de Renart, 2 vol. Paris : U.G.E.

Cormier, E. (2006). Diable et diableries : l'identité québécoise à travers les contes de chassegalerie. Mémoire présenté au Département d'études françaises de l'Université de Montréal sous la direction de M. Cambron.

Delcroix, A. Forissier, T. et Anciaux, F. (2013). Vers un cadre d'analyse opérationnel des phénomènes de contextualisation didactique. Dans F. Anciaux, T. Forissier et L. F. Prudent (dir.), Contextualisations didactiques. Approches théoriques (p. 141-185). Paris: L'Harmattan.

Demers, J. et Gauvain, L. (1976). Cinq versions de Rose Latulipe. Conte parlé, conte écrit, 12, 1-2, p.25-50. Montréal : Presses universitaires de Montréal.

Denzin, N.-K. et Lincoln, Y.-S. (2005). Introduction: The discipline and practice of qualitative research. Dans N.-K. Denzin et Y.-S. Lincoln (dir.), The SAGE handbook of qualitative research (p. 1-32). Thousand Oaks, CA : Sage.

Design-Based Research Collective. (2003). Design-based research : An emerging paradigm for educational inquiry. Educational Researcher, 32(1), 5-8.

Diabaté, A. (2014). Didactique du conte et enseignement-apprentissage du français langue de scolarisation à l'école élémentaire : état des lieux et perspectives. Sudlangues, 21, Consulté le 1 mars 2018 à l'adresse suivante :

http://www.sudlangues.sn/IMG/pdf/Didactique_du_conte_A_1_A_c_cole_A_c_1A_c_m entaireRTN.pdf.

Forissier, T. (2015). Conceptions d'étudiants scientifiques de Guadeloupe sur l'Observation de l'Orientation de la lune et des saisons climatiques. Dans A. Delcroix, J.-Y. Cariou, H. Ferriere et B. Jeannot-Fourcaud (dir.), Apprentissages, éducation, socialisation et contextualisation didactique: approches plurielles (p. 163-187). Paris : L'Harmattan.

Forissier, T., Bourdeau, J. et Psyché, V. (2018). Quand les contextes se comparent et se parlent. Contextes et Didactiques, 10, 111-122.

Gardes-Tamine, J. (1998). La Grammaire, tome 2 : la syntaxe. Paris : Armand Colin.

Gauthier, B. (2003). Recherche sociale. De la problématique à la collecte de données. Québec : Presses de 1'Université du Québec.

Guillou, M. (2014). Culture et lecture. Lille : Canopé.

Hazaël-Massieux, G. et Hazaël-Massieux, M.-C. (1996). Quel français parle-t-on aux Antilles? Dans D. de Robillard et M. Beniamino (dir.), le français dans l'espace francophone (p. 665-687). Paris : Champion.

Jardel, J.-P. (1977). Le conte créole. Sainte-Marie, Martinique/Université de Montréal : Centre de Recherches Caraïbes, Fonds Saint-Jacques.

Lacelle, N., Boutin, J.-F. et Lebrun, M. (2017). La littératie médiatique multimodale appliquée en contexte numérique. Outils conceptuels et didactiques. Québec: Presses de l'Université du Québec.

Lévi-Strauss, C. (1973). La structure et la forme. Réflexions sur un ouvrage de Vladimir Propp. Chapitre 8. Anthropologie structurale II (p. 139-173). Paris, France : Plon.

Ludwig, R., Poullet, H. et Bruneau-Ludwig, F. (2006). Le français guadeloupéen. Dans R. 
Confinat et R. Damoiseau (dir.), À l'arpenteur inspiré. Mélanges offerts à Jean Bernabé (p. 155-173). Matoury : Ibis Rouge éditions.

Moeschler, J. et Reboul, A. (1994). Dictionnaire encyclopédique de pragmatique. Paris : Armand Colin.

Popet, A. et Roques, E. (2000). Le Conte au Service de la Langue, cycle 2-cycle 3. Paris : Éditions Retz.

Propp, V. (1958). Morphologie du conte. Paris : Seuil/Points.

Relouzat, R. (1989). Le référent ethnoculturel dans le conte créole. Paris : L'Harmattan

Relouzat, R. (1998). Tradition Orale et Imaginaire Créole. Matoury : Ibis Rouge éditions.

Santerre, L. (1981). Le français québécois, langue ou dialiecte ? Québec français, 41, 26-27.

Saussure, F. de (1916). Cours de linguistique générale. Paris : Payot.

Senghor, L.-S. et Sadji, A. (1953). La Belle Histoire de Leuk-le-lièvre. Paris : Hachette.

Windmüller, F. (2008). Étude de l'adaptation interculturelle d'un conte commun à diverses cultures étrangères. L'exemple du Petit Chaperon rouge. Approche didactique et exploitation pédagogique. Recherche et pratiques en langues de spécialité. Cahiers de l'Apliut, 17. Disponible sur https://apliut.revues.org/1277.

Yavuz, F. et Celik, G.Y. (2017). Using fairy tales as a model to enhance learners' writing organization skill. International Journal of Learning and Teaching, 9(3), 349-353.

Zarior, S. (2016). Le conte, un outil au service de l'enseignement/apprentissage du Français Langue Étrangère. Tradtec, 15, 325-336. 


\title{
Annexe 1 : Conte guadeloupéen «Compère Zamba voulait tromper Compère Lapin »
}

\author{
Yé krik... Yé krak... \\ Yé mistikrik... Yé mistikrak...
}

Compère Lapin et Compère Zamba avaient toujours du mal à se comprendre mais ils étaient sans cesse ensemble, il étaient inséparables.

Dés que l'on voyait Lapin, on était sûr de voir Zamba qui le suivait.

Lapin cultivait son jardin et obtenait toujours une bonne récolte. Zamba lui aussi était un cultivateur mais sa récolte n'était pas tellement bonne car il ne suivait pas les règles de la lune et n'entretenait pas son champ.

Il disait :

- Moi, je n'ai pas de temps à perdre dans un jardin.

$$
\begin{aligned}
& \text { Mwenmenm pa ni tan } \\
& \text { Pou pèd an jaden } \\
& \text { Pa konté si mwen } \\
& \text { Pour sèklé jaden }
\end{aligned}
$$

Mais Zamba savait qu'il aurait toujours de quoi manger car Compère Lapin lui donnait toujours une part de sa récolte à ramener chez lui ainsi que les autres amis.

Seulement, quand les autres Compères ont remarqué que Zamba préférait traîner par les rues et n'était qu'un profiteur, ils décidèrent de ne plus rien lui donner.

$$
\begin{aligned}
& \text { Mwenmenm pa ni tan } \\
& \text { Pou pèd an jaden } \\
& \text { Pa konté si mwen } \\
& \text { Pour sèklé jaden }
\end{aligned}
$$

Quand Zamba constata que personne ne lui donnait quoi que ce soit, il alla auprès de Lapin et lui dit :

- Compère Lapin, plutôt que chacun fasse son jardin de son côté et gaspille des surfaces, nous n'avons qu'à produire un jardin à deux. Ainsi nous ferons moins d'effort.

- C'est d'accord! lui répondit Lapin.

- Et pour que nous ne connaissions pas de discorde, nous ferons ainsi : tout ce qui poussera vers le bas sera pour toi et ce qui poussera vers le haut sera pour moi.

Alors Zamba et Lapin coupèrent les arbres, labourèrent la terre. Mais quand arriva le moment de planter, Zamba disparut et Lapin dut tout planter tout seul. Zamba s'était fait passer pour malade.

Lapin planta des ignames, des patates, des malangas, des madères, du manioc...

Quand les plantes poussèrent, le jardin était beau. Zamba ne vint y arracher même pas un seul brin d'herbe. Compère Lapin soigna le jardin, il sarcla à la houe, mit des tuteurs aux ignames et le tout, tout seul.

Et puis le moment de la récolte arriva. Zamba alla voir Lapin et lui dit :

- Compère Lapin, il nous faut aller récolter le jardin.

- C'est d'accord! lui dit Lapin. Quand seras-tu prêt?

Quand ils allèrent récolter, pendant que Lapin fouillait les racines Zamba regardait sous les feuilles et ne trouvait rien. Quand il vit la quantité de vivres que Lapin tirait du sol, il lui dit :

- Tu m'as trompé !

- Ce n'est pas de ma faute! lui répondit Lapin. C'est toi-même qui as proposé que tout ce qui serait en haut serait à toi.

- Eh bien, l'année prochaine je veux tout ce qui est en bas et toi tu prendras ce qui est en haut! dit Zamba.

- Sans problème ! répondit Lapin.

Comme la première fois, quand arriva le moment de planter Zamba disparut. Il fit encore croire qu'il était malade. Lapin planta tout le champ tout seul. Il planta des adors, de la papaye, des gourdes, des christophines, du melon, des concombres, des bananiers...

Compère Lapin fit tout l'entretien du jardin tout seul. Pas un jour il ne vit Compère Zamba.

Le jardin devint beau et tout le monde venait auprès de Compère Lapin pour l'admirer.

Et quand le moment de la récolte arriva Compère Zamba vint à son tout :

- Lapin, Lapin! Allons récolter le jardin.

- C'est d'accord ! lui dit simplement Lapin.

Et Zamba vint avec sept sacs pour ramener sa récolte.

Pendant que Lapin cueillait les fruits de sa récolte sur les branches, Zamba fouillait. Et plus il creusait moins il trouvait.

\section{Être paresseux c'est contre soi même. Seul l'effort et le travail paient.}




\section{Annexe 2 : Conte québécois « Rose Latulipe »}

L'histoire de Rose Latulipe est aussi terrifiante que mystérieuse. Même si elle remonte au XVIIIème siècle, le destin tragique de cette jeune fille alimente encore aujourd'hui l'imaginaire collectif au Québec. C'était autour de l'an 1700. Pour ceux qui connaissent le petit village de Cloridorme, en Gaspésie, nul besoin de préciser l'allure de ce trou perdu plus longuement. Mais faisons-le quand même! Entre mer et montagnes, imaginons un petit amoncellement de cabanes hospitalières qui abritaient quelques familles de pêcheurs et de villageois, heureux de vivre et de défricher l'Amérique. À Cloridorme, qui ne s'amusait pas risquait de trouver le temps long. La petite Rose Latulipe était de celle qui préférait la fête. Elle profitait de chaque moment de bonheur qui s'offrait à elle. Plus que tout, elle aimait danser.

C'est son histoire que je vais vous conter. Cette histoire est bien réelle, croyez-moi, bien que la réalité ait largement dépassé la fiction. ${ }^{6}$

Rose était la fille unique d'un dénommé Latulipe. Celui-ci l'adorait, il tenait à elle comme à la prunelle de ses yeux. Et, il va sans dire, Latulipe ne pouvait rien refuser à sa fille.

À cette époque, pendant le carême, il était interdit de danser. Les quarante jours avant Pâques, on devait faire pénitence, et non s'amuser!

Rose était une jolie brunette, mais un peu éventée. Elle avait un amoureux nommé Gabriel, à qui elle était fiancée depuis peu. On avait fixé le mariage à Pâques. Rose aimait beaucoup les divertissements, si bien qu'un jour de Mardi gras, elle demanda à son père d'organiser une soirée de danse. Les quarante jours suivants, ce ne sera plus permis! Celui-ci accepta, bien sûr, mais il fit promettre à Rose que tous les invités seraient partis à minuit, car ce serait alors le Mercredi des Cendres. La soirée s'organisa : tout le monde vint veiller chez les Latulipe. Le violoneux du coin était là, tous dansaient, fêtaient et s'amusaient.

Il pouvait être onze heures du soir, lorsque tout à coup, au milieu d'un cotillon, on frappa à la porte. C'était un monsieur vêtu d'un superbe capot de chat sauvage.

Il demanda au maître de la maison la permission de se divertir un peu.

- C'est trop d'honneur nous faire, avait dit Latulipe, dégrayez-vous, donnez-moi votre manteau, votre chapeau, vos gants... s'il vous plaît, on va faire dételer votre cheval.

L'inconnu refusa de se dégrayer, prétextant qu'il ne resterait pas longtemps.

On lui offrit de l'eau-de-vie. L'inconnu n'eut pas l'air d'apprécier la boisson offerte. Il fit une grimace en l'avalant; car Latulipe, ayant manqué de bouteilles, avait vidé l'eau bénite de celle qu'il tenait à la main, et l'avait remplie d'alcool.

C'était un bel homme que cet étranger, mais il avait quelque chose de sournois dans les yeux.

Il invita la belle Rose à danser et ne l'abandonna pas de la soirée. Rose se laissa subjuguer par cet élégant jeune homme habillé de velours noir. Elle était la reine du bal.

Quant au pauvre Gabriel, renfrogné dans un coin, ne paraissait pas manger son avoine de trop bon appétit.

Une vieille tante, assise dans sa berceuse, observait la scène en disant son chapelet. À un certain moment, elle fit signe à Rose qu'elle voulait lui parler.

- Écoute, ma fille, lui dit-elle; j'aime pas ben ben ce monsieur, sois prudente. Quand il m'regarde avec mon chapelet, on dirait que ses yeux m'lancent des éclairs.

- Voyons donc, ma tante, dit Rose, continuez votre chapelet, et laissez les gens du monde s'amuser.

Minuit sonna. On oublia le Mercredi des Cendres.

- Encore une petite danse, dit l'étranger. Belle Rose, vous êtes si jolie, je vous veux. Soyez à moi pour toujours?

- Eh ben! oui, répondit-elle, un peu étourdiment.

- Donnez-moi votre main, dit-il, comme sceau de votre promesse.

Quand Rose lui présenta sa main, elle la retira aussitôt en poussant un petit cri, car elle s'était senti piquer; elle devint très pâle et dut abandonner la danse.

Mais l'étranger continuait ses galanteries auprès de la belle. Il lui offrit même un superbe collier en perles et en or : « Ôtez votre collier de verre, belle rose, et acceptez, pour l'amour de moi, ce collier de vraies perles. » Or, à ce collier de verre pendait une petite croix, et la pauvre fille refusait de l'ôter.

Pendant ce temps, deux jeunes gens qui étaient allés s'occuper du cheval de l'étranger avaient remarqué de bien étranges phénomènes. Le bel étalon noir était certes, une bien belle bête, mais pourquoi dégageait-il cette chaleur insupportable? Toute la neige sous ses sabots avait fondu. Ils rentrèrent donc et, discrètement, firent part à Latulipe de leurs observations.

Le curé, que Latulipe avait envoyé chercher, arriva; l'inconnu en tirant sur le fil du collier de verre de Rose l'avait rompu, et se préparait à saisir la pauvre fille, lorsque le curé, prompt comme l'éclair, s'écria d'une voix

\footnotetext{
${ }^{6}$ Version adaptée du conte Rose Latulipe à des fins pédagogiques à partir de deux versions disponibles sur ces sites : http://legendes-quebecoises.e-monsite.com/blog/cuisine/rose.html et http://litmedmod.ca/sites/default/files/pdf/Histoires_Endiablees_Cahier_enseignant.pdf.
} 
tonnante :

- Qu'est-ce tu fais icitte, parmi les chrétiens?

- Cette jeune fille s'est donnée à moi et le sang qui a coulé de sa main est le sceau qui me l'attache pour toujours, répliqua Lucifer.

- Va-t’en, Satan, s'écria le curé. Il prononça des mots latins que personne ne comprit.

Le diable disparut aussitôt avec un bruit épouvantable en laissant une odeur de soufre dans la maison. Tout le monde au village comprit aussitôt que l'inconnu n'était nul autre que le diable, venu pour inciter les gens à danser passé minuit. Il avait gardé son chapeau pour cacher ses cornes et ses gants pour cacher ses griffes.

Cinq ans après, une foule de curieux s'étaient réunis dans l'église, de grand matin, pour assister aux funérailles d'une religieuse. Parmi l'assistance, un vieillard déplorait en sanglotant la mort d'une fille unique, et un jeune homme, en habit de deuil, faisait ses derniers adieux à celle qui fut autrefois sa fiancée : la malheureuse Rose Latulipe. 


\section{Annexe 3 : Questionnaire à destination des élèves}

\section{QUESTIONNAIRE SUR LE CONTE}

NOM :

PRÉNOM :

SEXE: ÂGE : CLASSE :

Répondre aux questions suivantes :

1/ Est-ce que tu aimes les contes ? Peux-tu expliquer pourquoi?

2/ D'après toi, à quoi ça sert un conte?

3/ Pour toi, qu'est-ce qu'un conte ? Peux-tu expliquer ce que c'est un conte pour toi en quelques phrases

4/ Dessine ce à quoi tu penses quand tu entends le mot « conte ».

5/ Quels sont les mots et les expressions souvent utilisées dans un conte ? Peux-tu donner quelques exemples de mots et d'expressions que l'on retrouve souvent dans un conte?

6/ Quels sont les personnages que l'on retrouve souvent dans un conte ? Peux-tu donner quelques exemples de noms de personnages de contes que tu connais ?

7/ Dans quels types de lieux se passent généralement les contes ? Peux-tu donner quelques exemples de lieux dans lesquels se déroulent des contes ?

8/ Quelles sont les différentes étapes, les différents moments dans un conte ? Peux-tu donner les différentes parties d'un conte?

9/ Quels sont les différentes choses de ta vie de tous les jours que tu peux retrouver dans un conte?

10/ Écris en quelques mots et dessine ce qui t'a impressionné (ou surpris) dans les échanges avec les élèves de l'autre classe 


\section{Annexe 4 : Protocole d'entretien avec les élèves sur leur dessin}

Ce protocole court a pour objectif d'aider les chercheurs à préparer les entretiens individuels avec les enfants qui ont participé à l'expérimentation pour revenir sur les dessins qu'ils ont produit à la question $\mathrm{n}^{\circ} 4$ « Dessine ce à quoi tu penses quand tu entends le mot "conte"».

La durée de l'entretien est de 5 minutes pour chaque enfant.

Pour passer les entretiens, il faut choisir un espace isolé sans bruit dans l'école pour installer la caméra et accueillir l'élève. Le chercheur se met en face de l'élève. La caméra doit être placée devant l'élève.

Le chercheur lance l'enregistrement vidéo, salue l'élève, lui demande son prénom et son âge, clarifie les objectifs de l'entretien et il commence par présenter le dessin réalisé par l'élève lors du pré-test.

L'entretien est prévu en trois étapes et débute alors à partir de la phrase d'introduction suivante dite par le chercheur : "Est-ce que tu peux m'expliquer ce que tu as dessiné ? ». Ensuite, l'élève explique ce qu'il a dessiné et le chercheur fait quelques relances afin que tous les éléments du dessin et leurs relations soient explicités.

Puis, une seconde question est posée à l'élève par le chercheur : "Pourquoi tu as décidé de représenter le conte avec ce dessin? ». Cette question permet aux élèves d'évoquer la problématique de leur dessin.

Enfin, une troisième et dernière question est posée par le chercheur : «Est-ce que tu as déjà vu ça que tu as dessiné ? Si oui, où as-tu vu ce que tu as dessiné ? ». Si besoin, l'intervieweur relance des questions afin qu'il comprenne à quelle réalité le dessin fait référence.

Le chercheur répète le même processus avec l'élève pour le dessin qu'il a réalisé lors du post-test.

Dans un dernier temps, le chercheur peut poser les questions suivantes visant à comprendre le rapport qu'entretient l'élève avec le conte: «Est-ce que tu lis souvent des contes?»; «Est-ce que tu écris des contes?»; «Quand tu étais petit(e), quelqu'un te lisait-il des contes? Si oui, c'était qui ?».

Le chercheur remercie l'élève de sa participation et arrête l'enregistrement vidéo. 
Annexe 5 : Exemples d'images proposées aux élèves

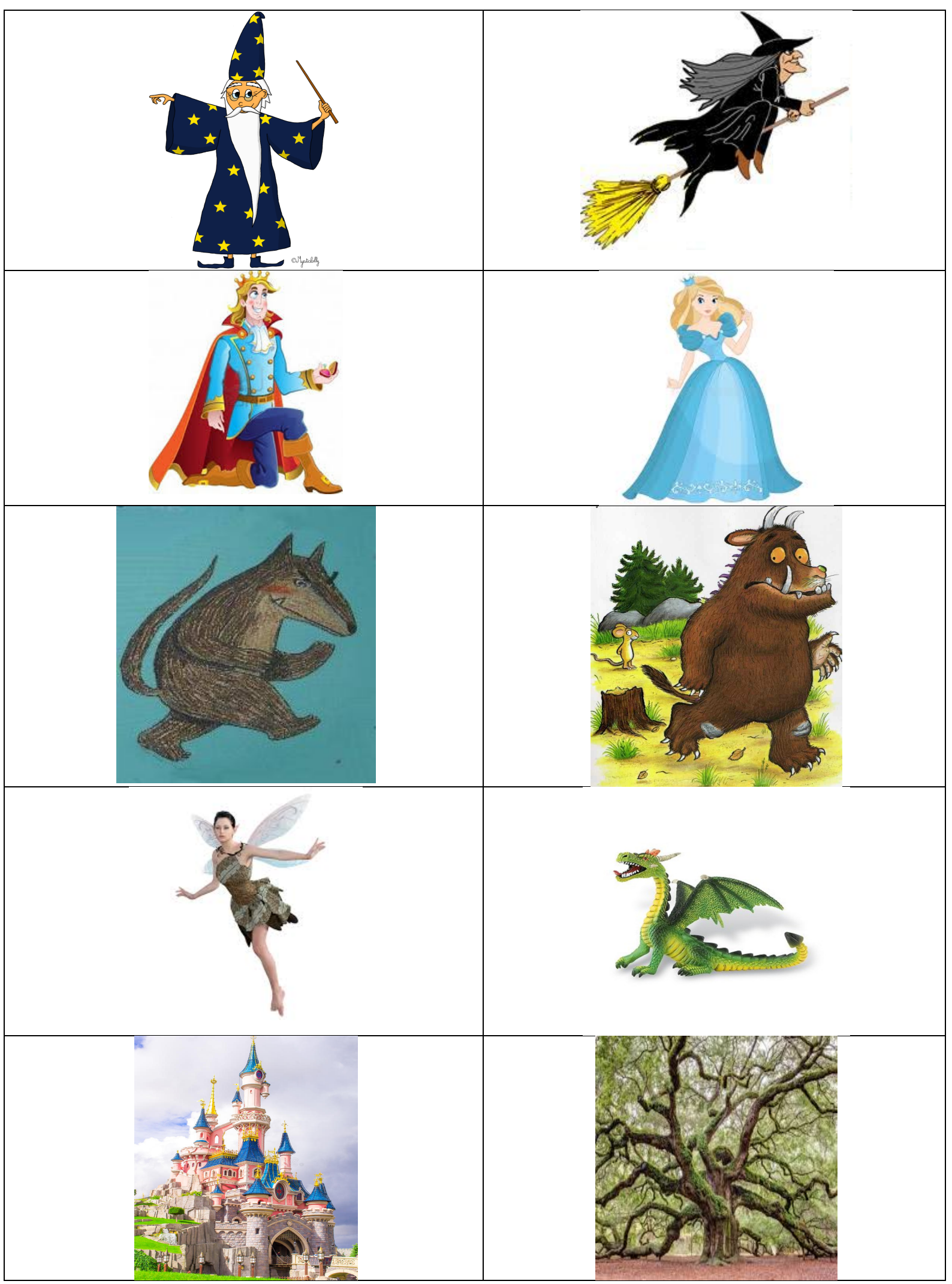




\section{Annexe 6 : Fréquences d'apparitions des mots relatifs aux caractéristiques du conte}

\begin{tabular}{|c|c|c|c|c|c|c|}
\hline \multicolumn{7}{|c|}{ Caractéristiques des contes } \\
\hline \multirow{2}{*}{ Catégories } & \multirow{2}{*}{ Unités lexicales } & \multicolumn{2}{|c|}{ Guadeloupe } & \multicolumn{2}{|c|}{ Québec } & \multirow{2}{*}{ Tota } \\
\hline & & Pré-test & Post-test & Pré-test & Post-test & \\
\hline Support & Livre & 2 & 2 & 0 & 0 & 4 \\
\hline \multirow{3}{*}{ Culture } & Existe dans différentes cultures & 1 & 0 & 0 & 0 & 1 \\
\hline & Créole(s) & 2 & 2 & 0 & 0 & 4 \\
\hline & Culture(s) & 1 & 0 & 0 & 0 & 1 \\
\hline Uniquement réel & Existe & 1 & 0 & 0 & 0 & 1 \\
\hline \multirow{4}{*}{ Uniquement irréel } & N'existe pas & 1 & 0 & 0 & 1 & 2 \\
\hline & Faits irréels & 1 & 0 & 0 & 0 & 1 \\
\hline & Lieux irréels & 0 & 1 & 0 & 0 & 1 \\
\hline & Lieux imaginaires & 0 & 2 & 0 & 0 & 2 \\
\hline \multirow{4}{*}{ Irréel et réel } & Monde imaginaire ou pas quelque fois & 0 & 0 & 0 & 1 & 1 \\
\hline & Éléments fictifs et réels & 0 & 0 & 0 & 1 & 1 \\
\hline & Personnage fictif ou réel & 0 & 0 & 0 & 1 & 1 \\
\hline & Fragments réels & 0 & 0 & 1 & 0 & 1 \\
\hline Période & Moyen-Âge & 0 & 1 & 0 & 0 & 1 \\
\hline \multirow{12}{*}{ Histoire } & Irréelle & 0 & 1 & 0 & 1 & 2 \\
\hline & Magique & 0 & 0 & 1 & 0 & 1 \\
\hline & Adorable & 0 & 0 & 1 & 0 & 1 \\
\hline & Créative & 0 & 0 & 1 & 0 & 1 \\
\hline & Courte & 0 & 0 & 1 & 1 & 2 \\
\hline & Inspirée d'une histoire vraie ou non & 0 & 0 & 1 & 1 & 2 \\
\hline & Vraie transformée en conte & 0 & 0 & 0 & 1 & 1 \\
\hline & Coloriée & 0 & 0 & 0 & 1 & 1 \\
\hline & Fictive & 0 & 0 & 0 & 1 & 1 \\
\hline & Dans le passé & 0 & 0 & 0 & 1 & 1 \\
\hline & Pas réaliste & 0 & 0 & 0 & 1 & 1 \\
\hline & Classique & 0 & 0 & 1 & 0 & 1 \\
\hline \multirow{3}{*}{ Fin } & Termine bien ou mal & 0 & 1 & 0 & 1 & 2 \\
\hline & Contient toujours une fin heureuse & 0 & 0 & 1 & 0 & 1 \\
\hline & Une morale & 0 & 1 & 0 & 1 & 2 \\
\hline \multirow{12}{*}{ Divers } & Raconté par un spécialiste & 0 & 1 & 0 & 0 & 1 \\
\hline & Lit avant le coucher & 0 & 1 & 0 & 0 & 1 \\
\hline & Conteur écrit & 0 & 1 & 0 & 0 & 1 \\
\hline & Utilisé pour les enfants & 0 & 0 & 1 & 0 & 1 \\
\hline & Lecture des parents aux enfants & 0 & 0 & 0 & 1 & 1 \\
\hline & Légende & 0 & 0 & 0 & 2 & 2 \\
\hline & Rêve & 0 & 0 & 0 & 1 & 1 \\
\hline & Film & 0 & 0 & 0 & 1 & 1 \\
\hline & Présence de magie & 0 & 0 & 0 & 1 & 1 \\
\hline & Bonheur et joie & 0 & 0 & 0 & 1 & 1 \\
\hline & Courage & 0 & 0 & 0 & 1 & 1 \\
\hline & Super cool & 0 & 0 & 0 & 1 & 1 \\
\hline & Total & 9 & 14 & 9 & 23 & 55 \\
\hline
\end{tabular}


Annexe 7 : Fréquences d'apparition des expressions relatives aux contes

\begin{tabular}{|c|c|c|c|c|c|c|}
\hline \multicolumn{7}{|c|}{ Expressions du conte } \\
\hline \multirow{2}{*}{ Catégories } & \multirow{2}{*}{ Unités lexicales } & \multicolumn{2}{|c|}{ Guadeloupe } & \multicolumn{2}{|c|}{ Québec } & \multirow{2}{*}{ Tota } \\
\hline & & Pré-test & Post-Test & Pré-test & Post-Test & \\
\hline \multirow{12}{*}{$\begin{array}{c}\text { Début (temps et } \\
\text { espace) }\end{array}$} & Il était une fois & 8 & 9 & 6 & 6 & 29 \\
\hline & C'était une fois & 0 & 0 & 0 & 1 & 1 \\
\hline & Il y a très longtemps & 1 & 0 & 1 & 0 & 2 \\
\hline & Il y a longtemps & 0 & 1 & 0 & 0 & 1 \\
\hline & Il y a bien longtemps & 0 & 0 & 0 & 1 & 1 \\
\hline & Il y a fort longtemps & 0 & 0 & 0 & 1 & 1 \\
\hline & Il y a & 0 & 0 & 0 & 1 & 1 \\
\hline & Un beau jour dans un château & 1 & 0 & 0 & 0 & 1 \\
\hline & Un beau jour & 0 & 0 & 1 & 0 & 1 \\
\hline & un jour & 1 & 1 & 0 & 0 & 2 \\
\hline & Dans un pays magique & 0 & 0 & 0 & 1 & 1 \\
\hline & Dans un pays lointain & 0 & 1 & 1 & 0 & 2 \\
\hline \multirow{9}{*}{$\begin{array}{l}\text { Milieu } \\
\text { (déclenchement } \\
\text { et péripéties) }\end{array}$} & par hasard & 0 & 0 & 1 & 0 & 1 \\
\hline & jadis & 0 & 0 & 1 & 0 & 1 \\
\hline & Soudain & 0 & 0 & 1 & 1 & 2 \\
\hline & cependant & 0 & 0 & 1 & 0 & 1 \\
\hline & Heureusement & 0 & 0 & 0 & 2 & 2 \\
\hline & C'est à ce moment là que & 0 & 0 & 0 & 1 & 1 \\
\hline & Tout à coup & 0 & 0 & 3 & 1 & 4 \\
\hline & C'est alors que & 0 & 0 & 1 & 0 & 1 \\
\hline & mon prince vient me sauver à l'aide & 0 & 0 & 1 & 0 & 1 \\
\hline \multirow[b]{2}{*}{ Fin } & Depuis ce temps & 0 & 0 & 0 & 1 & 1 \\
\hline & $\begin{array}{l}\text { Ils vécurent heureux et (eurent) (eus) } \\
\text { auront plein (beaucoup d') } \\
\text { (nombreux) (plusieurs)enfants }\end{array}$ & 0 & 0 & 2 & 2 & 4 \\
\hline $\begin{array}{l}\text { Expression } \\
\text { typique conte }\end{array}$ & Abracadabra & 0 & 0 & 0 & 3 & 3 \\
\hline \multirow{12}{*}{$\begin{array}{l}\text { Expressions } \\
\text { typiques contes } \\
\text { créoles }\end{array}$} & Est-ce que la cour dort? & 1 & 4 & 0 & 0 & 5 \\
\hline & Non, la cour ne dort pas. & 1 & 3 & 0 & 0 & 4 \\
\hline & $\begin{array}{l}\text { C'est Isidor qui dort sur son oreiller } \\
\text { d'or pour deux sous d'or (à Pointe } \\
\text { d'or) }\end{array}$ & 1 & 2 & 0 & 0 & 3 \\
\hline & Dlo doubout & 1 & 1 & 0 & 0 & 2 \\
\hline & Dlo doubout, Canne & 0 & 1 & 0 & 0 & 1 \\
\hline & Dlo pann & 1 & 1 & 0 & 0 & 2 \\
\hline & Dlo pann, Coco & 0 & 1 & 0 & 0 & 1 \\
\hline & Yékrik Yékrak & 1 & 20 & 0 & 0 & 21 \\
\hline & Yémistikri(k) Yémistikra(k) & 1 & 19 & 0 & 0 & 20 \\
\hline & Mistikrak mistikrik & 0 & 0 & 0 & 1 & 1 \\
\hline & Krik Krak (croque) & 1 & 0 & 0 & 1 & 2 \\
\hline & Gendanm an ban dlo & 0 & 1 & & 0 & 1 \\
\hline \multirow{3}{*}{$\begin{array}{l}\text { Expressions } \\
\text { québécoises }\end{array}$} & Va tile chair (s'asseoir à une table) & 0 & 1 & & 0 & 1 \\
\hline & $\begin{array}{l}\text { Tire-toi une bûche (va prendre une } \\
\text { chaise : va te tirer une bûche) }\end{array}$ & 0 & 0 & 0 & 2 & 2 \\
\hline & Qu'est-ce tu fais icitte? & 0 & 0 & 0 & 1 & 1 \\
\hline
\end{tabular}


Revue « Contextes et Didactiques », n ${ }^{\circ} 1$, Juin 2018

\begin{tabular}{|c|l|c|c|c|c|c|}
\hline \multirow{2}{*}{$\begin{array}{c}\text { Expressions } \\
\text { françaises }\end{array}$} & Dormir comme une bûche & 0 & 0 & 1 & 0 & $\mathbf{1}$ \\
\cline { 2 - 6 } & $\begin{array}{l}\text { Chercher une aiguille dans une botte } \\
\text { de foin }\end{array}$ & 0 & 0 & 1 & 0 & $\mathbf{1}$ \\
\hline \multirow{4}{*}{$\begin{array}{c}\text { Autres } \\
\text { expressions }\end{array}$} & $\begin{array}{l}\text { Tu cognes dedans ce qui veut dire } \\
\text { qu'il est endormi }\end{array}$ & 0 & 0 & 1 & 0 & $\mathbf{1}$ \\
\cline { 2 - 7 } & Cayer des bras & 0 & 0 & 0 & 1 & $\mathbf{1}$ \\
\cline { 2 - 7 } & Il avait un air de leveuf & 0 & 0 & 0 & 1 & $\mathbf{1}$ \\
\hline \multirow{3}{*}{$\begin{array}{c}\text { Fonction des } \\
\text { expressions }\end{array}$} & Garder l'attention & 0 & 0 & 0 & 1 & $\mathbf{1}$ \\
\cline { 2 - 7 } & Attirer l'attention & 0 & 2 & & 0 & $\mathbf{2}$ \\
\cline { 2 - 7 } & Débuter & $\mathbf{1 9}$ & $\mathbf{6 8}$ & $\mathbf{2 3}$ & $\mathbf{3 1}$ & $\mathbf{1 3}$ \\
\hline
\end{tabular}


Annexe 8 : Fréquences d'apparition des mots relatifs aux contes

\begin{tabular}{|c|c|c|c|c|c|c|}
\hline \multicolumn{7}{|c|}{ Mots du conte } \\
\hline \multirow{2}{*}{ Catégories } & \multirow{2}{*}{ Unités lexicales } & \multicolumn{2}{|c|}{ Guadeloupe } & \multicolumn{2}{|c|}{ Québec } & \multirow{2}{*}{ Total } \\
\hline & & Pré-test & Post-Test & Pré-test & Post-Test & \\
\hline \multirow{3}{*}{ Lieux } & Château & 2 & 0 & 0 & 0 & 2 \\
\hline & Forêt magnifique & 0 & 0 & 1 & 0 & 1 \\
\hline & Royaume & 0 & 0 & 1 & 0 & 1 \\
\hline \multirow{3}{*}{ Objet } & Carrosse & 1 & 0 & 0 & 0 & 1 \\
\hline & Cloche & 1 & 0 & 0 & 0 & 1 \\
\hline & Couronne & 1 & 0 & 0 & 0 & 1 \\
\hline \multirow{8}{*}{ Personnages } & Nains & 1 & 0 & 0 & 0 & 1 \\
\hline & Princesse & 1 & 0 & 1 & 0 & 2 \\
\hline & Sorcière & 1 & 0 & 0 & 0 & 1 \\
\hline & La petite Brunette & 0 & 2 & 0 & 0 & 2 \\
\hline & Charmante jeune fille & 0 & 0 & 0 & 1 & 1 \\
\hline & Jolie mademoiselle & 0 & 0 & 0 & 1 & 1 \\
\hline & Titi & 0 & 1 & 0 & 0 & 1 \\
\hline & Prince & 0 & 0 & 1 & 0 & 1 \\
\hline \multirow{3}{*}{ Territoire } & Antillais & 0 & 1 & 0 & 0 & 1 \\
\hline & Créole & 0 & 1 & 0 & 0 & 1 \\
\hline & Français & 0 & 2 & 0 & 0 & 2 \\
\hline Autres & Magie & 0 & 0 & 1 & 0 & 1 \\
\hline \multicolumn{2}{|r|}{ Total } & 8 & 7 & 5 & 2 & 22 \\
\hline
\end{tabular}


Annexe 9 : Fréquences d'apparition des personnages relatifs aux contes

\begin{tabular}{|c|c|c|c|c|c|c|}
\hline \multicolumn{7}{|c|}{ Personnage de contes } \\
\hline \multirow{2}{*}{ Catégories } & \multirow{2}{*}{ Unités lexicales } & \multicolumn{2}{|c|}{ Guadeloupe } & \multicolumn{2}{|c|}{ Québec } & \multirow{2}{*}{ Tota } \\
\hline & & Pré-test & Post-Test & Pré-test & Post-Test & \\
\hline \multirow{13}{*}{$\begin{array}{l}\text { Personnages de } \\
\text { contes créoles }\end{array}$} & Konpe Lapin & 10 & 22 & 0 & 1 & 33 \\
\hline & Konpe Zamba & 4 & 20 & 0 & 1 & 25 \\
\hline & Konpe Taureau & 1 & 0 & 0 & 0 & 1 \\
\hline & Konpe Chauval & 1 & 0 & 0 & 0 & 1 \\
\hline & La Diablesse & 0 & 1 & 0 & 0 & 1 \\
\hline & Ti Derodie & 0 & 4 & 0 & 0 & 4 \\
\hline & Ti Sapotille & 0 & 5 & 0 & 0 & 5 \\
\hline & Ti Jean & 0 & 1 & 0 & 0 & 1 \\
\hline & Ti diable & 0 & 2 & 0 & 0 & 2 \\
\hline & Compère & 0 & 2 & 0 & 4 & 6 \\
\hline & Bet-a-Man-Ibè & 0 & 1 & 0 & 0 & 1 \\
\hline & Soukounyan & 0 & 1 & 0 & 0 & 1 \\
\hline & Volant & 0 & 1 & 0 & 0 & 1 \\
\hline \multirow{2}{*}{$\begin{array}{l}\text { Personnages du } \\
\text { conte québécois }\end{array}$} & Diable & 0 & 3 & 0 & 4 & 7 \\
\hline & Rose Latulipe & 0 & 7 & 0 & 2 & 9 \\
\hline \multirow{29}{*}{$\begin{array}{l}\text { Personnages de } \\
\text { contes connus }\end{array}$} & Belle & 2 & 0 & 1 & 1 & 4 \\
\hline & Belle et le clochard & 1 & 0 & 0 & 0 & 1 \\
\hline & Belle et la Bête & 4 & 1 & 2 & 0 & 7 \\
\hline & La Belle au bois dormant & 0 & 1 & 0 & 1 & 2 \\
\hline & Fée des dents & 0 & 0 & 0 & 1 & 1 \\
\hline & Fée clochette & 3 & & 1 & 0 & 4 \\
\hline & Petite sirène & 3 & 1 & 1 & 2 & 7 \\
\hline & Reine des neiges & 2 & 1 & 0 & & 3 \\
\hline & Blanche Neige & 4 & 3 & 0 & 2 & 9 \\
\hline & $\begin{array}{l}\text { Blanche Neige et les sept } \\
\text { nains }\end{array}$ & 2 & 1 & 2 & 0 & 5 \\
\hline & Petit chaperon rouge & 2 & 3 & 1 & 0 & 6 \\
\hline & Raiponce & 5 & 1 & 2 & 1 & 9 \\
\hline & Cendrillon & 3 & 2 & 5 & 2 & 12 \\
\hline & Marraine de Cendrillon & 0 & 0 & 0 & 1 & 1 \\
\hline & Ariel & 1 & 0 & 2 & 0 & 3 \\
\hline & Aurore & 1 & 0 & 0 & 0 & 1 \\
\hline & Pinokio & 1 & 1 & 0 & 0 & 2 \\
\hline & Vaiana & 1 & 1 & 0 & 0 & 2 \\
\hline & $\begin{array}{l}\text { Alice au pays des } \\
\text { merveilles }\end{array}$ & 0 & 0 & 2 & 0 & 2 \\
\hline & Prince Jack & 0 & 0 & 2 & 0 & 2 \\
\hline & Romeo et Juliette & 0 & 0 & 1 & 0 & 1 \\
\hline & La souris verte & 0 & 0 & 1 & 0 & 1 \\
\hline & Les gourmands & 0 & 0 & 1 & 0 & 1 \\
\hline & Les trois petits cochons & 0 & 0 & 3 & 1 & 4 \\
\hline & Boucles d'or & 0 & 0 & 1 & 0 & 1 \\
\hline & Mickey Mouse & 0 & 0 & 1 & 0 & 1 \\
\hline & Judy & 0 & 1 & 0 & 0 & 1 \\
\hline & Les Schtroumpfs & 0 & 1 & 0 & 1 & 2 \\
\hline & Père Noël & 0 & 0 & 0 & 1 & 1 \\
\hline
\end{tabular}


Revue « Contextes et Didactiques », ${ }^{\circ} 11$, Juin 2018

\begin{tabular}{|c|c|c|c|c|c|c|}
\hline & Capitaine Crochet & 0 & 0 & 0 & 1 & 1 \\
\hline & Jim Mathieu & 0 & 0 & 1 & 0 & 1 \\
\hline & Dracula & 0 & 1 & 0 & 0 & 1 \\
\hline \multirow{10}{*}{ Types d'humains } & Fées & 2 & 0 & 2 & 1 & 5 \\
\hline & Rois & 1 & 2 & 3 & 1 & 7 \\
\hline & Reine & 2 & 2 & 3 & 1 & 8 \\
\hline & Princesses & 4 & 5 & 8 & 9 & 26 \\
\hline & Princes & 3 & 4 & 4 & 2 & 13 \\
\hline & Chevalier & 2 & 0 & 4 & 3 & 9 \\
\hline & Sorcière & 1 & 1 & 0 & 0 & 2 \\
\hline & Garde & 1 & 0 & 0 & 0 & 1 \\
\hline & Nains & 0 & 0 & 1 & 1 & 2 \\
\hline & Soldat & 0 & 0 & 0 & 1 & 1 \\
\hline \multirow{5}{*}{ Type d'animaux } & Loup & 0 & 0 & 1 & 1 & 2 \\
\hline & Cigale & 0 & 0 & 1 & 0 & 1 \\
\hline & Fourmis & 0 & 0 & 1 & 0 & 1 \\
\hline & Cochon & 0 & 0 & 1 & 1 & 2 \\
\hline & Lapin & 0 & 2 & 0 & 2 & 4 \\
\hline \multirow{8}{*}{ Type de monstres } & Dragons & 2 & 1 & 4 & 4 & 11 \\
\hline & Monstres & 1 & 1 & 1 & 1 & 4 \\
\hline & Ogre & 1 & 0 & 0 & 0 & 1 \\
\hline & Elfe & 0 & 0 & 1 & 0 & 1 \\
\hline & Lutin & 0 & 0 & 1 & 1 & 2 \\
\hline & Loup-garou & 0 & 0 & 0 & 2 & 2 \\
\hline & Cheval-loup & 0 & 0 & 0 & 1 & 1 \\
\hline & Fantôme & 0 & 0 & 0 & 1 & 1 \\
\hline \multirow{14}{*}{$\begin{array}{l}\text { Caractéristiques des } \\
\text { personnages }\end{array}$} & Animaux & 0 & 3 & 0 & 4 & 7 \\
\hline & Humains & 0 & 3 & 0 & 1 & 4 \\
\hline & Fille & 0 & 0 & 0 & 1 & 1 \\
\hline & Garçon & 0 & 0 & 0 & 1 & 1 \\
\hline & Drôles & 0 & 1 & 0 & 0 & 1 \\
\hline & Fantastiques & 0 & 1 & 0 & 0 & 1 \\
\hline & Gentils & 0 & 1 & 0 & 0 & 1 \\
\hline & Réels & 0 & 1 & 0 & 0 & 1 \\
\hline & Inventées & 0 & 1 & 0 & 0 & 1 \\
\hline & Méchants & 0 & 3 & 0 & 2 & 5 \\
\hline & Imaginaires & 0 & 0 & 0 & 1 & 1 \\
\hline & Fictifs & 0 & 0 & 0 & 2 & 2 \\
\hline & Maléfique & 0 & 0 & 1 & 0 & 1 \\
\hline & Géantes & 0 & 0 & 0 & 1 & 1 \\
\hline \multicolumn{2}{|l|}{ Total } & 71 & 121 & 67 & 73 & 332 \\
\hline
\end{tabular}


Revue « Contextes et Didactiques », n ${ }^{\circ} 1$, Juin 2018

Annexe 10 : Fréquences d'apparition des types de lieux

\begin{tabular}{|c|c|c|c|c|c|}
\hline \multicolumn{6}{|c|}{ Lieux de contes } \\
\hline \multirow{2}{*}{ Unités lexicales } & \multicolumn{2}{|c|}{ Guadeloupe } & \multicolumn{2}{|c|}{ Québec } & \multirow{2}{*}{ Total } \\
\hline & Pré-test & Post-Test & Pré-test & Post-Test & \\
\hline forets & 9 & 12 & 11 & 12 & 44 \\
\hline châteaux & 6 & 10 & 13 & 11 & 40 \\
\hline jardin & 0 & 16 & 0 & 1 & 17 \\
\hline maison(s) & 0 & 5 & 5 & 5 & 15 \\
\hline lieux & 0 & 8 & 2 & 2 & 12 \\
\hline rue & 0 & 7 & 1 & 0 & 8 \\
\hline village & 0 & 2 & 1 & 4 & 7 \\
\hline pays & 3 & 1 & 1 & 1 & 6 \\
\hline école & 3 & 1 & 1 & 0 & 5 \\
\hline ville & 2 & 2 & 0 & 0 & 4 \\
\hline rivière & 1 & 3 & 0 & 0 & 4 \\
\hline champs & 0 & 2 & 1 & 1 & 4 \\
\hline mondes & 2 & 0 & 1 & 0 & 3 \\
\hline tour(s) & 1 & 0 & 1 & 1 & 3 \\
\hline endroit & 1 & 1 & 0 & 0 & 2 \\
\hline donjon & 0 & 0 & 2 & 0 & 2 \\
\hline palais & 0 & 0 & 0 & 2 & 2 \\
\hline mer & 1 & 0 & 1 & 0 & 2 \\
\hline plage & 1 & 1 & 0 & 0 & 2 \\
\hline bois & 0 & 1 & 1 & 0 & 2 \\
\hline grottes & 0 & 1 & 1 & 0 & 2 \\
\hline nuages & 0 & 1 & 1 & 0 & 2 \\
\hline ciel & 0 & 0 & 1 & 1 & 2 \\
\hline immeuble & 0 & 0 & 1 & 0 & 1 \\
\hline chambre & 1 & 0 & 0 & 0 & 1 \\
\hline royaumes & 0 & 0 & 1 & 0 & 1 \\
\hline arbres & 0 & 1 & 0 & 0 & 1 \\
\hline campagne & 0 & 1 & 0 & 0 & 1 \\
\hline ferme & 0 & 0 & 0 & 1 & 1 \\
\hline contrée & 0 & 0 & 0 & 1 & 1 \\
\hline TOTAL & 31 & 76 & 47 & 43 & 197 \\
\hline
\end{tabular}


Annexe 11 : Graphiques des types de connaissances en fonction des questions, des territoires et des moments d'évaluation

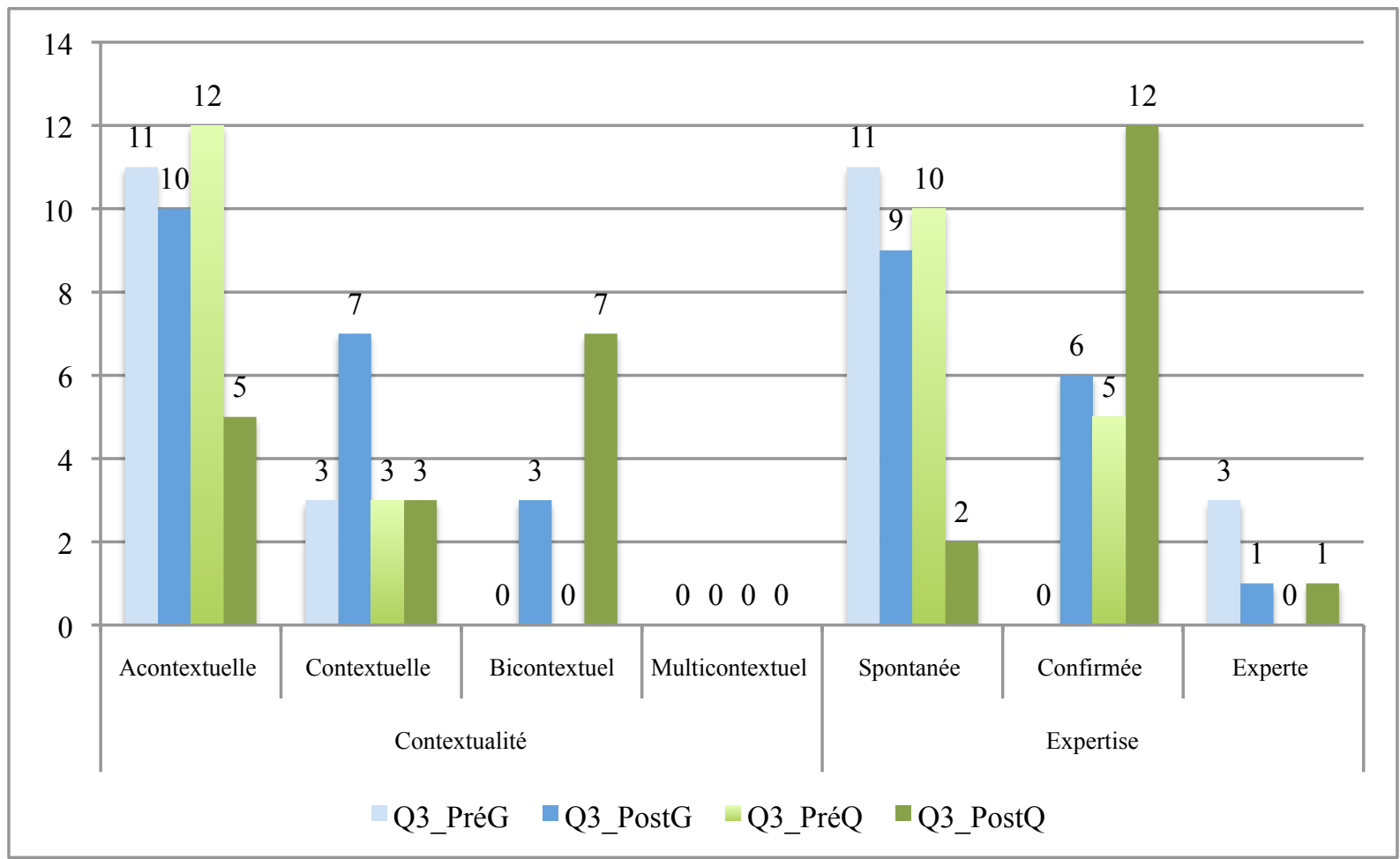

Graphique 7 : Niveau d'expertise et de contextualité des réponses à la question $\mathbf{n}^{\circ} 3$

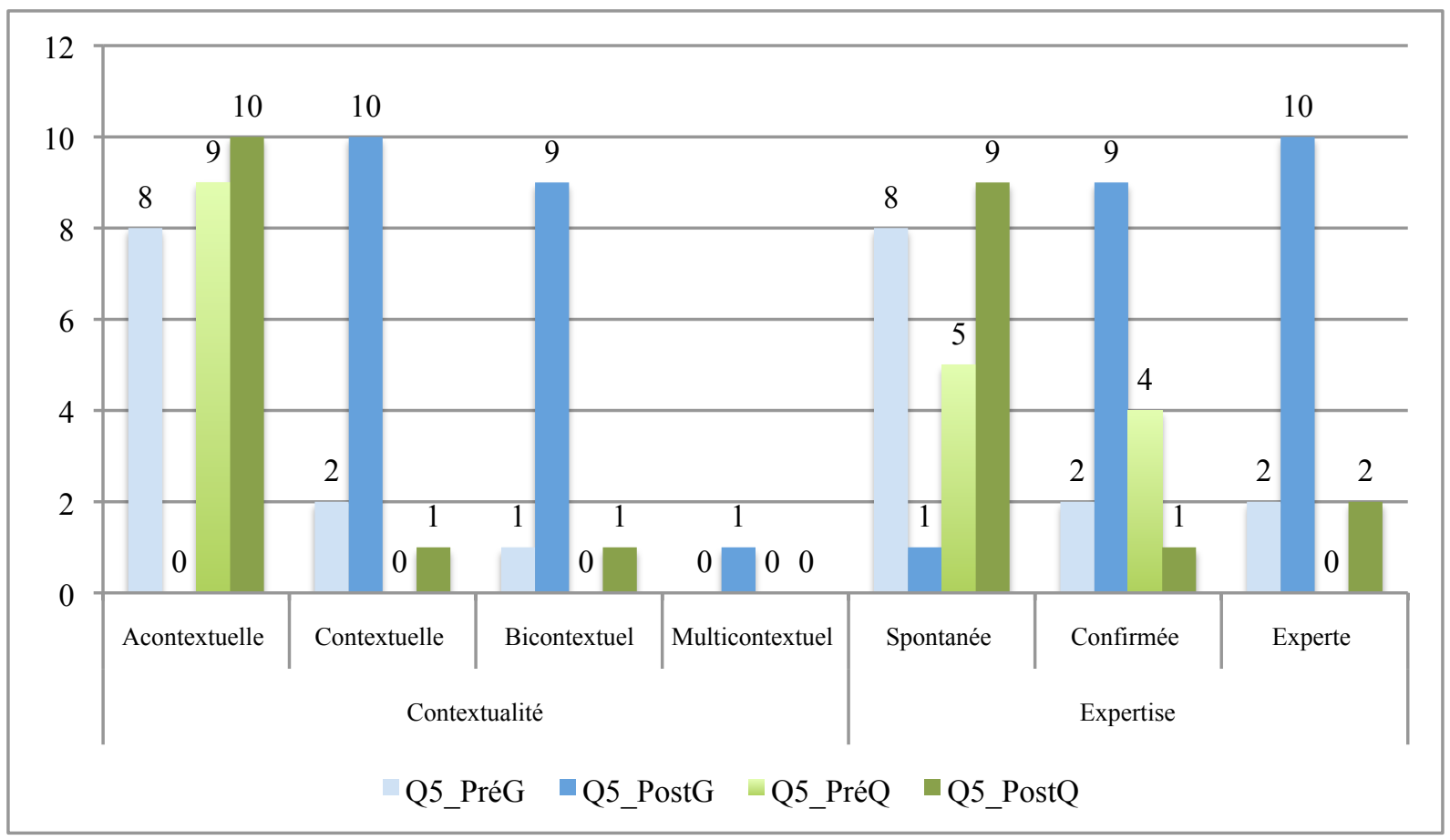

Graphique 8 : Niveau d'expertise et de contextualité des réponses à la question $\mathbf{n}^{\circ} 5$ 


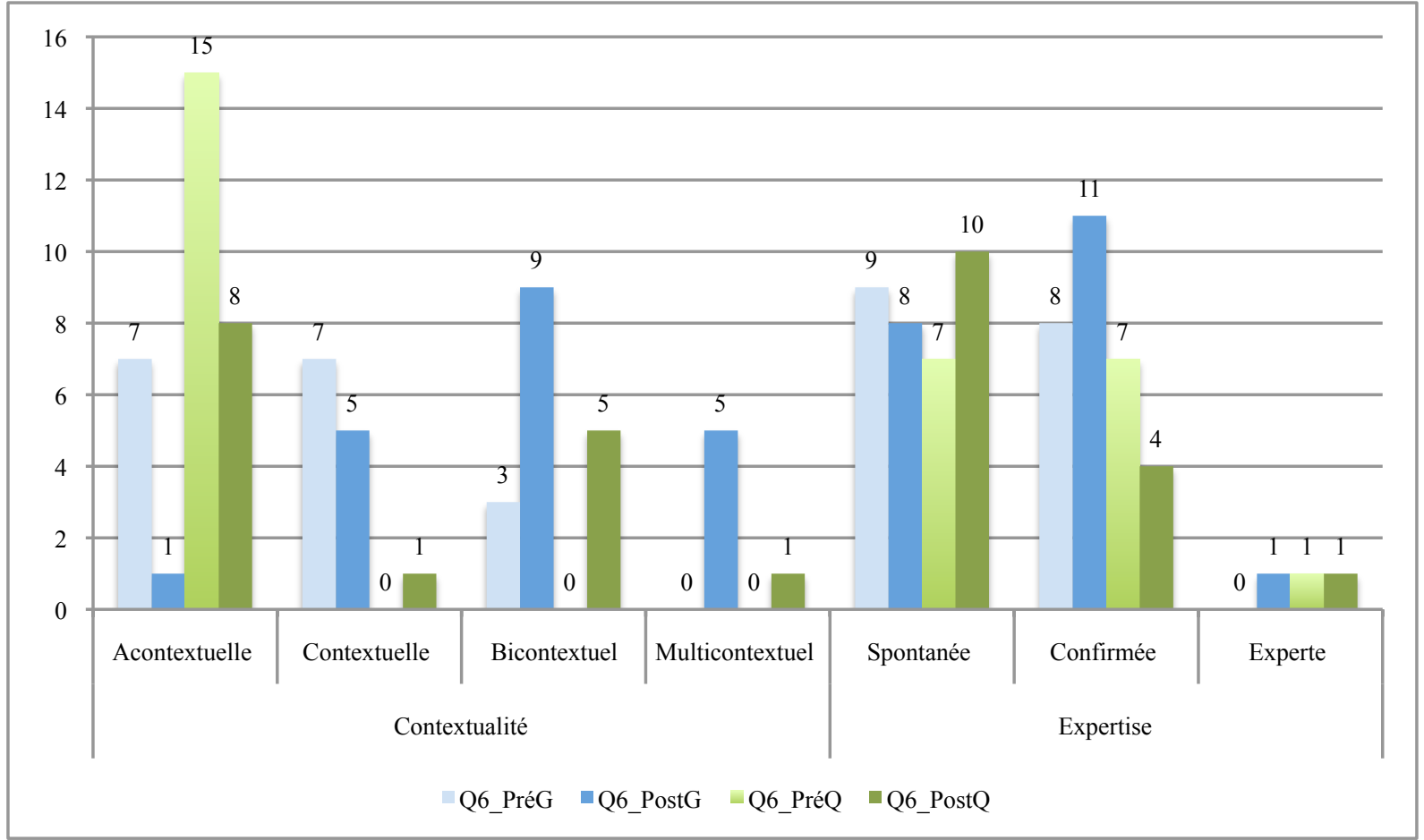

\section{Graphique 9 : Niveau d'expertise et de contextualité des réponses à la question $\mathbf{n}^{\circ} 6$}

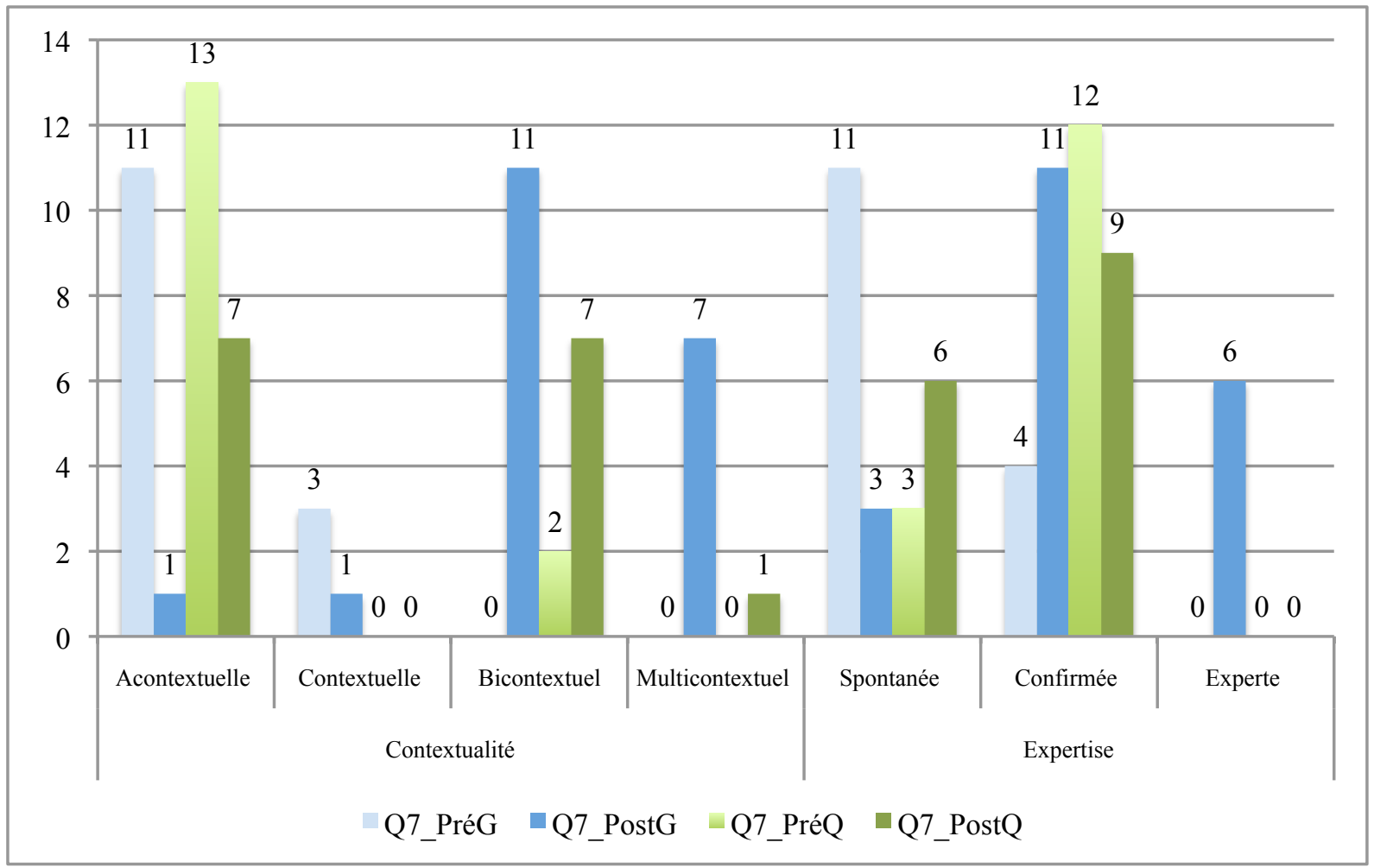

Graphique 10 : Niveau d'expertise et de contextualité des réponses à la question $\mathbf{n}^{\circ} 7$ 
Revue « Contextes et Didactiques », n¹1, Juin 2018 